\title{
Access to Surgical Care in Rural Ecuador and the Role of Cinterandes Mobile Surgery in Addressing Barriers and Delays: A Qualitative and Biosocial Research Analysis
}

\section{Citation}

Vega, Martha Paola. 2017. Access to Surgical Care in Rural Ecuador and the Role of Cinterandes Mobile Surgery in Addressing Barriers and Delays: A Qualitative and Biosocial Research Analysis. Master's thesis, Harvard Medical School.

\section{Permanent link}

http://nrs.harvard.edu/urn-3:HUL.InstRepos:41940992

\section{Terms of Use}

This article was downloaded from Harvard University's DASH repository, and is made available under the terms and conditions applicable to Other Posted Material, as set forth at http:// nrs.harvard.edu/urn-3:HUL.InstRepos:dash.current.terms-of-use\#LAA

\section{Share Your Story}

The Harvard community has made this article openly available.

Please share how this access benefits you. Submit a story.

\section{Accessibility}


This Thesis, Access to Surgical Care in Rural Ecuador \&

the Role of Cinterandes Mobile Surgery in Addressing Barriers and Delays:

a Qualitative \& Biosocial Research Analysis, presented by Martha Paola Vega, MD and Submitted to the Faculty of The Harvard Medical School in Partial Fulfillment of the

Requirements for the Master of Medical Sciences in Global Health Delivery in the

Department of Global Health and Social Medicine has been read and approved by:

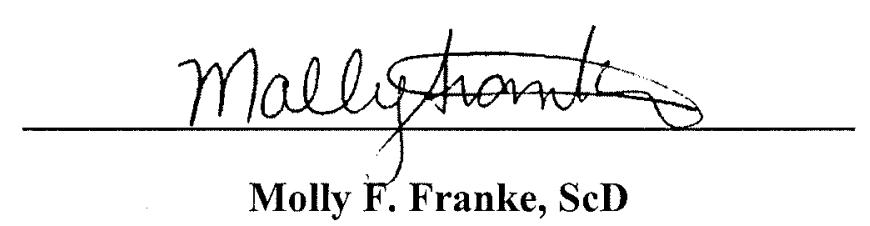

Molly F. Franke, ScD

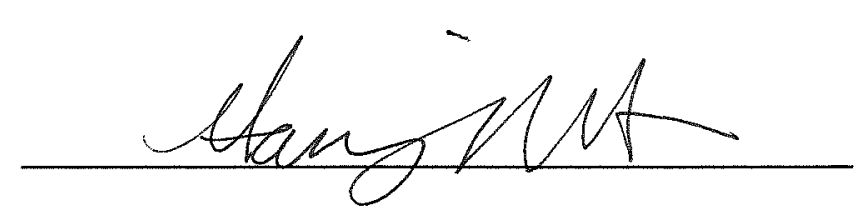

Hannah N. Gilbert, Ph.D

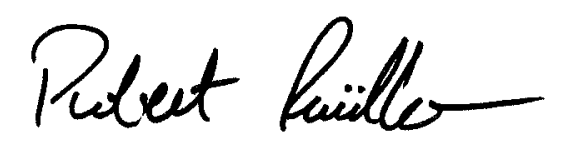

Robert Riviello, MD, MPH

Date: August 25, 2017 
ACCESS TO SURGICAL CARE IN RURAL ECUADOR AND THE ROLE OF CINTERANDES MOBILE SURGERY IN ADDRESSING BARRIERS AND DELAYS: A QUALITATIVE AND BIOSOCIAL RESEARCH ANALYSIS

\author{
MARTHA PAOLA VEGA, MD
}

\author{
A Thesis Submitted to the Faculty of \\ The Harvard Medical School \\ in Partial Fulfillment of the Requirements \\ for the Degree of Master of Medical Sciences in Global Health Delivery \\ in the Department of Global Health and Social Medicine \\ Harvard University \\ Boston, Massachusetts.
} August 23, 2017 
Thesis Advisors:

Martha P. Vega

Molly F. Franke, ScD

Hannah N.Gilbert, PhD,

Robert Riviello MD MPH

Access to Surgical Care in Rural Ecuador \&

The Role of Cinterandes Mobile Surgery in Addressing Barriers and Delays:

A Qualitative \& Biosocial Research Analysis

\begin{abstract}
Timely access to surgical care is crucial to the development of resilient healthcare systems, society and economic growth (Meara et al., 2015). Using a biosocial approach, this study aimed to (1) identify and understand barriers, delays and facilitators affecting rural patients' surgical care access; and (2) investigate the role that Cinterandes mobile surgery plays in surgical care in five rural Ecuadorian communities. This qualitative assessment employed an inductive, content analytic approach to document experiences and opinions on accessing surgical services in rural Ecuador. We sought to understand the perspectives on surgical access from a variety of informants including rural patients, healthcare providers, healthcare workers, healthcare leaders and rural community leaders. We conducted 36 multi-vocal semistructured interviews to include participants from five rural communities within Azuay and Cañar provinces in the Andean highlands, Morona-Santiago province in the Amazon rainforest, and Santa Elena province in the coastal region; and also interviewed members of the Cinterandes Foundation, an Ecuadorian mobile surgery program.
\end{abstract}


We found nine barriers and delays in the care seeking process of rural patients. These include unfamiliarity with hospitals, doctors and urban settings; the responsibility of the family unit, distrust in the public healthcare system, health system inefficiencies, displacement of decision-making power, strong regulations on non-governmental organizations, unique remoteness of the Amazon, the negative impact that lack of supplies has on delivery of surgical care, and the conflict between the assumptions and practices about rural patient's use of traditional medicine. In addition, we found three facilitators including (1) the benefit of the family unit; (2) Socialización (an educational process that brings together rural patients and physicians to deepen patients' understandings of surgical illness, surgical care and break biosocial barriers); and (3) the importance of surgeons or physicians visiting patients' homes. In analyzing biosocial issues, we found that structural violence embedded in historical, social, political and healthcare system structures hindered rural patient's ability to access surgical care. We described how Cinterandes mobile surgery addresses the three delays in surgical care and described the Cinterandes mobile surgery model of care. Moreover, we redefined Cinterandes mobile surgery as a CommunityBased Surgical Care Accompaniment Model. Based on this analysis we offer recommendations that we hope will inform and guide future decisions to optimize the surgical care delivery system and help decrease barriers to surgical care for rural patients. 


\section{Table of Contents}

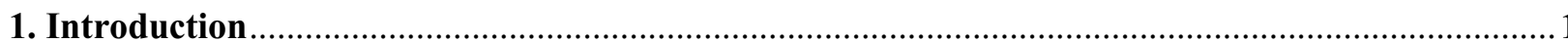

1.1 Access to Surgical Care Error! Bookmark not defined.

1.2 Why Study Access to Surgical Care in Rural Ecuador?......................................................

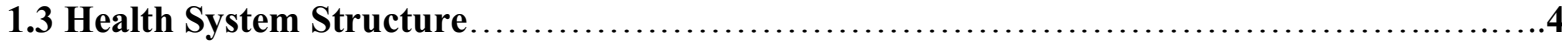

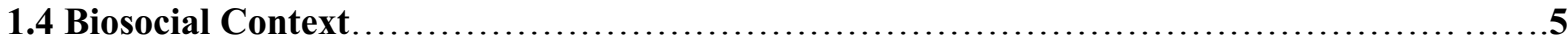

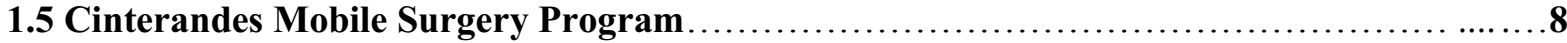

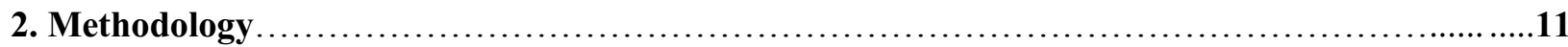

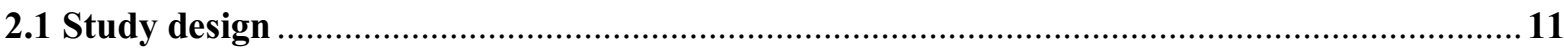

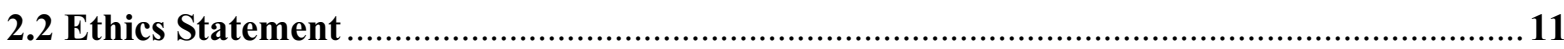

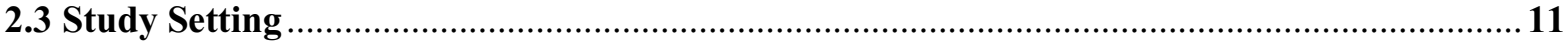

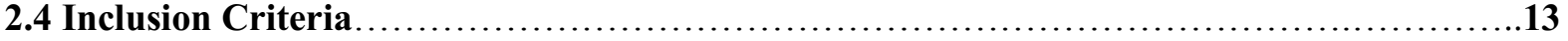

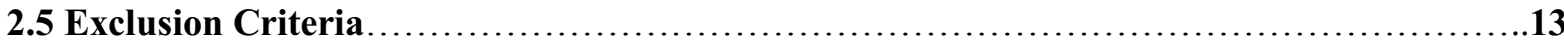

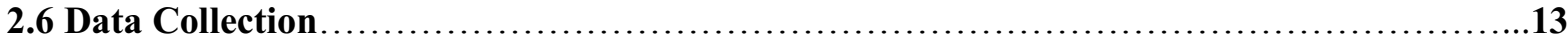

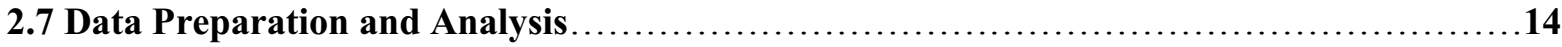

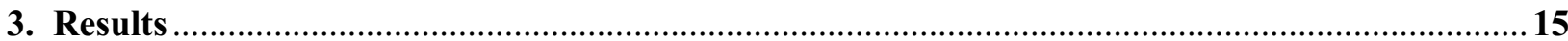

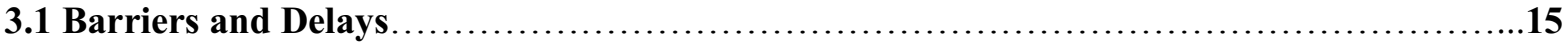

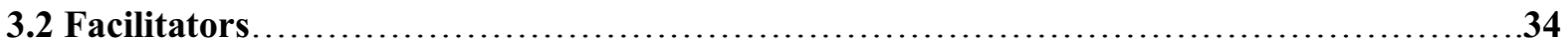

3.3 How Cinterandes Mobile Surgery Overcomes Surgical Access Barriers and Delays............39

3.4 Understanding the Cinterandes Mobile Surgery Model of Care $\ldots \ldots \ldots \ldots \ldots \ldots \ldots \ldots \ldots . \ldots 3$

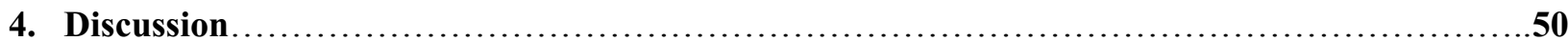

4.1 Analysis for Barriers, Delays \& Facilitators..................................................

4.2 Structural Violence Embedded in the History and

Social Fabric of Rural Populations and Healthcare Structures.........................76

4.3 Redefining Cinterandes Mobile Surgery:

Community-Based Surgical Care Accompaniment Model............................78

4.4 Recommendation for Surgical Stakeholders $\ldots \ldots \ldots \ldots \ldots \ldots \ldots \ldots \ldots \ldots \ldots \ldots \ldots \ldots \ldots \ldots 1$

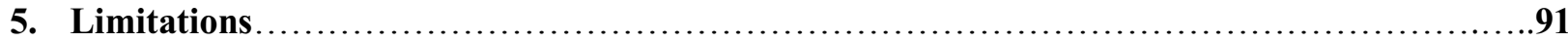

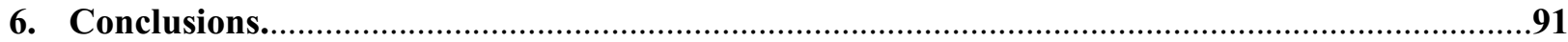




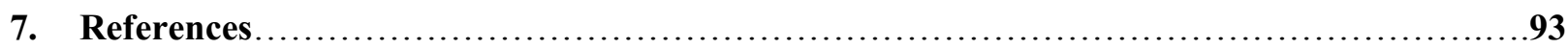

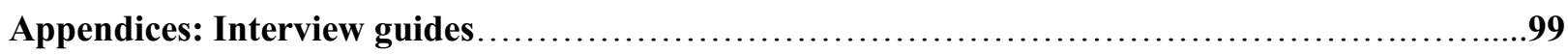


Figures

Figure 1: Cinterandes Mobile Surgical Unit Design..............................10 
Tables

Table 1: Total and Rural Populations by Provinces..............................

Table 2: Model for Long-term Cinterandes Mobile Surgical Mission

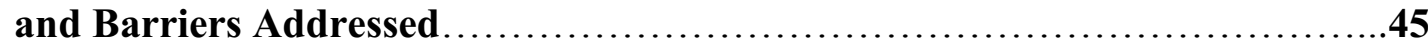

Table 3: Cinterandes' Community-Based Surgical Care Accompaniment Model.........79 
Dedicated to the Loving Memory of

My Grandmother

Mamáma

\author{
A humble woman from the \\ Peruvian Andes \\ who walked in solidarity with \\ the less fortunate
}




\section{Acknowledgements}

I would like to first thank my Father God, Lord Jesus and Holy Spirit for their amazing love and the opportunity, support and guidance to develop this research project in benefit of the beautiful people of rural Ecuador. May He receive all the glory for the accomplishments of this work.

Wholeheartedly, I'd like to thank my mom, Martina Medina, for her everlasting love, encouragement and support. Without her example of courage, sacrificial love and excellence, I wouldn't have had the capacity to dream and explore the extent of my faith in my career and in developing this project. I would also like to thank my sister Miluska, her husband Henry and my nephew Ethan for their love, understanding, support and enthusiasm for my global health work. I am also grateful to my best friend Yvette who has been an amazing encourager during every step of my project. And I am grateful for my extended Christian church family, in particular to my dear friend Jeannie for her support and prayers while I was away in the field.

I am absolutely blessed and honored to have been guided and shaped by each of my Master of Medical Sciences in Global Health Delivery Program Mentors at Harvard Medical School.

Dr. Molly Franke, my principal mentor, thank you for believing in my work and for supporting the development of this project. I am very grateful for your mentorship and amazing commitment during these last two years. Your wisdom and academic excellence have been invaluable components for the success of our project. Thank you for investing in my academic growth, and for helping me achieve my best. Muchísimas gracias.

Dr. Hannah Gilbert, my qualitative research methods mentor, thank you for walking along side me to teach me the process of developing rigorous qualitative research. I am grateful for your guidance and for helping me develop the skills I need to succeed. I take with me your example of humble generosity and enthusiasm during every phase of the project. It was exciting to see through your eyes how significant this project was, even during its early stages.

Dr. Robert Riviello, my global surgery mentor from the Program in Global Surgery and Social Change, I am grateful for your support in this project and for believing in its value. Thank you for nurturing my ability to explore and develop my research capacity. You are an awesome global surgeon, and an excellent role model. Dios bendiga tu gran labor en todo el mundo.

Dr. Joia Mukherjee, thank you so much for your amazing support in my career as global health researcher and for the development of this research project. I am honored to have been taught by you. Thank you for the work you have sacrificially done in my country Peru. I admire your courage and devotion for advocacy. Your zeal for social justice inspires me to transform the world around me. This program has changed my life. Muchísimas gracias.

Dr. Paul Farmer, thank you for inspiring me to believe that positive social change is possible for the vulnerable people of the Andes, Amazon and rural Coast of South America. When I first heard of your remarkable work in Peru in the 1990's, I knew at that moment, this is the type of doctor I wanted to be. I never imagined I would be blessed to have your mentorship, or that I would become a Paul Farmer Global Surgery Research Fellow and a graduate student of the MMSc-GHD Program, both of which you helped create. Dios te bendiga inmensamente. 
Dr. John Meara, thank you for your enthusiastic support for my research work in mobile surgery and global surgery work in Latin America. I have learned from you and the PGSSC team essential skills to answer socially relevant surgical questions which I plan to apply towards optimizing surgical care systems in rural Latin America and beyond. Thank you for your trust.

A special acknowledgement to Christina Lively, MMSc-GHD Program Coordinator, I am grateful for your wonderful and sacrificial support. Thank you for ensuring my success in the program and for your valuable contribution to the development of this project. You are absolutely amazing and a strong pillar to our program. To each faculty member of the MMScGHD program, thank you for your devotion teaching us high quality research skills and to Dr. Lisa Hirschhorn thank you for your guidance in the development of this project.

To the incredible Cinterandes Mobile Surgery Team, I would like to recognize your extraordinary work. You along with Dr. Edgar Rodas Andrade, are a great inspiration to me. I am so honored and humbled to have worked with you. Thank you for allowing me to be part of your team. Each of you has made valuable contributions to this project. In the most sincere way, thank you very much for your support, wisdom, dedication, love and friendship. You are examples of solidarity and selflessness for the noble service of the vulnerable. My commitment to Cinterandes does not end here; we will continue to work together towards the expansion of mobile surgery. (De la manera más sincera, muchísimas gracias por su apoyo, dedicación, cariño y muy especial amistad. Son un ejemplo de solidaridad para noble servicio de los más vulnerables.)

With my most sincere appreciation, I'd like to thank the leadership of Hospital Homero Castanier Crespo for their great support and enthusiasm in the development of this project. I'd like to acknowledge their excellence serving rural patients in Ecuador. Their high standards of care, dedication, kindness and respect for the rural communities are greatly admirable.

I am grateful for my MMSc-GHD friends. Your friendship, academic richness and shared enthusiasm for our research accomplishments have been a great inspiration. May each of you impact how medicine is practiced around the world to promote high standards of global health care; and may we continue to enrich each other in our efforts to contribute towards social equity.

To everyone, may you continue to be blessed with wisdom for the success of your global health endeavors. Yuminsajme ${ }^{l}$.

This work was conducted with support from the Master of Medical Sciences in Global Health Delivery program of Harvard Medical School Department of Global Health and Social Medicine and financial contributions from Harvard University and the Abundance Fund. The content is solely the responsibility of the authors and does not necessarily represent the official views of Harvard University and its affiliated academic health care centers.

1 Yuminsajme, expression in Shuar by poet Maria Clara Sharupi Jua: "in this expression of thanks, the person gives all of their love to the other person, not as if that person is simply a person to whom love is directed, but as if that person is actually an extension of one's self." (Kelly, 2012) 


\section{INTRODUCTION}

\subsection{Access to Surgical Care}

Access to surgical care is shaped by complex health system-centered and patient-centered conditions, processes, behaviors, and biosocial patterns. Surgical barriers have been identified in resource limited settings. In a systematic literature review of barriers to surgical access in low and middle-income countries by Grimes and colleagues, financial and structural barriers were among the most common reasons (Grimes et al., 2011). More specifically, poor roads, lack of suitable transport, lack of local resources, a lack of surgical expertise, direct and indirect costs of surgery, and fear of undergoing surgery and anesthesia, were frequent contributors (Grimes et al., 2011). In a landmark study by the Lancet Commission on Global Surgery (LCoGS) and their global assessment of surgical care, Meara and colleagues estimated that over 5 billion people in the world lack access to surgical services (Meara et al, 2015). Barriers were classified into three main delays in surgical care access: the delay in seeking care (first delay), the delay in reaching care (second delay), and the delay in receiving care (third delay) (Meara et al., 2015). For example, rural communities' history of being disconnected from formal health systems and low confidence in surgical services have contributed to the first delay (Meara et al, 2015). Long distances to surgical facilities have contributed to the second delay (Meara et al, 2015). The scarcity of surgical capacity or the fact that "arriving to a hospital does not guarantee treatment", have contributed to the third delay (Meara et al., 2015, p.580). Barriers to surgical access are multiple and complex, therefore if effective local interventions to improve surgical access are desired, locally-relevant analyses of existing surgical care access is required.

Current knowledge of surgical care barriers comes predominantly from studies in Africa and Asia. Surgical care access in rural Latin America is under-explored. In recent years, data have brought increased awareness about the inequitable distribution of surgical services between high and low-income 
settings; rural communities lack the access to surgical services that is often found in urban settings (Atiyeh et al., 2010). We needed to assess region-specific surgical access barriers so that in the future practical solutions could be developed to target specific local needs. We hypothesized that biosocial barriers place rural populations of Ecuador at a disadvantage to access timely surgical care. In order to help guide future surgical care delivery restructuring efforts, we sought to identify and comprehend barriers, delays and facilitators that affect surgical access. Furthermore, we seek to better understand the role of the Cinterandes mobile surgery program in optimizing access to surgery for Ecuadorian rural and indigenous populations.

\subsection{Why Study Access to Surgical Care in Rural Ecuador?}

Ecuador's rural population accounts for $36 \%$ of its total population (World Bank, 2015). Compared to their urban counterparts, rural populations worldwide face a greater risk of impoverishment as a result of undergoing a surgical procedure (Meara et al., 2015). Therefore in Ecuador, 5.8 million people have greater financial vulnerability than the remaining two-thirds of its population if faced with the need for surgery. Despite national economic growth in the last 10 years and decreasing national poverty, 55.8\% of the rural population lives in poverty. This is far above the national average of $32.9 \%$. This marked socioeconomic inequity makes rural populations more vulnerable to disease, which may in turn perpetuate their poverty.

Surgical care can address a significant proportion of the global burden of disease (Shrime et al., 2015). Conservatively, the 2002 World Health Report's global burden of disease estimated that $11 \%$ of illness can be attributed to surgically manageable conditions (Debas et al., 2006). A more recent analysis by Shrime and colleagues showed that surgical conditions account for $28-32 \%$ of the total burden of disease (Shrime et al., 2015). According to Rose and colleagues, surgery is involved in the care of all disease 
categories present at all stages of life, and non-communicable diseases are among the most common conditions requiring surgical care (Rose et al, 2014). In Ecuador, a large proportion of disability is attributed to non-communicable diseases (WHO Ecuador, 2014); therefore surgical care expansion in the country can potentially address a large proportion of its burden of disease.

According to the Lancet Commission on Global Surgery (LCoGS) and the World Health Organization (WHO), it is economically profitable for a country to invest in surgical care (Meara et al., 2015 \& Orgediz, 2008). LCoGS estimated that in order to meet strategic 2030 global surgery strategic expansion, it would cost developing countries 350 billion dollars, but failing to invest in surgery would cost 12.3 trillion dollars which translate into slowed or declining economic and social development (Meara et al., 2015). The expansion of surgical care access, including access by rural populations, is necessary and a profitable social capital investment. The identification and understanding of barriers to improve surgical access will inform key surgical stakeholders to develop effective surgical care strategies.

The need to study rural surgical access and invest in their care is not only compelled by its financial benefits. Liberation theology's preferential option for the poor describes the moral urgency to prioritize the needs of the most vulnerable in society. According to liberation theologian Gustavo Gutiérrez, "the various challenges to human life — economic, political, environmental, and medical—may seem disconnected from theology, but they are not" (Gutiérrez \& Farmer, 2013, p. 28). He highlights that poverty is not a result of fate, but of human made structures. Impoverished patients should be given priority in the provision of care as an effort to liberate them from structures created by "the sin of social injustice and exclusion" (Gutiérrez \& Farmer, 2013, p. 28). Using a biosocial lens this study aimed to identify and understand such structures that affect or deter a rural patient's ability to access surgical care. 
This moral responsibility of the preferential option for the poor has been adopted by the World Bank in its efforts to end extreme poverty and promote social development (Kim, 2016). On April, 2015, 140 faith-based organizations and leaders in collaboration with the World Bank and United Nations officials developed a faith-based action framework with the goal of ending poverty and realizing the Sustainable Development Goals (Clark, 2016). The World Bank Group also recognizes that the "vast majority of the global poor live in rural areas" (World Bank, 2016). Global surgery and global health academics, leaders, advocates, and students must assume the moral responsibility to help rural populations affected by surgical disease and contribute to the improvement of surgical care access. Sub-optimal access to surgical care directly or indirectly contributes to poverty and halts rural populations' social development.

For the reasons presented, and because rural patient access to surgical care in Ecuador has never been assessed, understanding surgical care access specifically among rural populations is of particular importance. We hope to identify areas in the surgical care system that may need to be addressed or optimized to improve rural population's access to surgery and thereby make a contribution towards their social development.

\subsection{Healthcare System Structure}

Ecuador's national healthcare system is a government universal healthcare model. Healthcare as a right was instituted in the country's 2008 Constitution during the leadership of former President Rafael Correa and his political party's introduction of the post-neoliberal Citizen's Revolution movement. The central healthcare governing body is the Ministry of Public Health (Ministerio de Salud Pública), which is subdivided into multiple administrative zonal institutions to ensure the implementation and regulation of healthcare practices and policy. The Ministry of Health delegates responsibilities to nine zones which are responsible for the management of their provincial healthcare institutions. 
The public healthcare system is comprised of Ministry of Health public hospitals and health posts, health sub-center, and health centers. Their services are available to the whole population. Then, the National Institute of Social Security (IESS -Instituto Ecuatoriano del Seguro Social) is also integrated in the public system. It mainly provides healthcare services through worker's insurance. In addition, the public system collaborates with a network of private healthcare institutions via a referral system, which are utilized when services are unavailable at the public institutions (DePaepe, 2012). In spite of the free surgical care offered by the Ecuadorian government, we hypothesize rural populations confront barriers which may not be currently considered by the healthcare system.

\subsection{Biosocial Context}

\section{1) Structural Violence}

In this study, we will explore how structural violence affects surgical care access. According to Dr. Paul Farmer, structural violence in embedded in "invisible social structures" which "impair human life" by inequitable access to resources that would otherwise ensure basic needs (Farmer, 2006, e449). Structural violence is associated with social disparities where "racism, gender inequality, poverty, political violence and war often determine who falls ill and who has access to care" (Farmer, 2006, e449). It is used by the “social machinery of oppression" (Farmer, 2004, p.307). We suspect social structures which cause structural violence affect rural patient's ability to access care. In Ecuador, healthcare is a constitutional human right (Asamblea, 2008) and surgical care should be considered likewise. Therefore any structure

that directly or indirectly infringes on surgical access equity will be considered a contributor to structural violence. Throughout this study we will elucidate social, political, historical or healthcare structures that contribute to structural violence against rural populations hindering their ability to access timely surgery. 


\section{2) Socio-Political Context Affecting Rural Populations}

Historically, this country has been greatly impacted by colonialism. Ecuador was conquered by the Inca Empire during the $15^{\text {th }}$ century and by the Spanish during the $16^{\text {th }}$ century (Alchon, 1991). Colonialism was marked by violence and subjugation of native people. Spanish conquerors created social structures forcing native Ecuadorians to work in benefit of the Spanish crown (Alchon, 1991). Today's rural populations are mainly indigenous ethnic groups such as the Kichwas and Shuar among others. Modern rural populations continue to be affected by colonialism, and we will see how colonial legacies are embedded in contemporary social and political practices.

In recent history, Ecuador has been marked by great political, economic and social instability. It underwent a dictatorship between 1976 and 1979. Then, like most Latin American countries, it endured a neoliberal era between 1982 and 2007 that was largely defined by multiple structural reforms, which directed the country into economic decline (Conaghan, 2016). A major economic crisis in 1999 led to the dollarization of the currency at the turn of the millennium. Between 1997 and 2007, the country was governed by eight different presidents, two of who were overthrown, Jamil Mahuad in 2000 and Lucio Gutiérrez in 2005.

Post-neoliberalism became well-established during the former presidency of Rafael Correa who won elections in 2006. His leadership regained social and political stability for the country. He remained in power for ten years under his political party Country Alliance (Alianza País), which continues to exercise control now under the current presidency of Lenin Moreno. Despite the overall political stability, President Correa was not exempt from manifestations and great social discontent. He endured an attempted coup d'état in the year 2000 in which the police forces tried to overthrow the government by kidnapping former President Correa at a hospital in Quito, the capital. 
Currently, Ecuadorian society and its healthcare structure exist in the context of the country's National Plan for Sumak Kawsay, which in the native kichwa language means Good Living (Plan Nacional del Buen Vivir). Instituted during Correa's presidency, this plan aimed to consolidate a democratic state and construct popular power through socialism, pluralism and anti-neoliberal ideologies, which went on to shape the Ecuadorian social and healthcare structures. The plan also established the protection of human and environmental rights as well as addressed social inequalities among vulnerable populations, including indigenous people. It claimed to implement anti-neoliberal concepts of "social solidary" which are aimed to "eradicate the principle of selfish personal development, characteristic of a society of free market" (Desarrollo, 2013). Ironically, rural and indigenous populations and organizations have expressed great discontent with the actions of the government. They affirm indigenous people are experiencing social injustices (CONFENAIE, 2012).

During the beginning of former President Correa's term, his government introduced numerous laws and agreements. One of these was the establishment of the Yasuni-ITT trust in June 2007, in which the Yasuni ecological reserve was protected from natural resource extraction (Ecuador, 2011). As part of the millennium development goals, the government agreed to abstain from the extraction of an estimated 846 million barrels of crude oil to prevent the emission of 407 million metric tons of CO2 (Ecuador, 2011). The government expected to collect 3.6 billion dollars from the international community over a period of 13 years, but this program failed (Erazo, 2013). In August, 2013 former President Correa signed the executive order \#74 to begin oil extraction in Yasuní, impacting rural communities' livelihood in the Amazon. 
Amazon rural populations are particularly vulnerable to the state's agenda to extract natural resources.

Crude oil and mining concessions are shaping the social landscape for rural communities (Davalos, 2014).

Communities that have historically lived in rural protected lands have been displaced by political structures that defend international oil and mining corporations. Northeastern and southeastern Ecuador, including the state of Morona-Santiago — which is part of our study — have crude oil, copper and gold reserves that are important to the global market. Exploitation of these natural resources has led to the displacement of indigenous communities from their native lands, such as those living in the Yasuni National Reserve (Davalos, 2014). There is a dichotomy between the anti-neoliberal discourse of the state and its social and political structures currently affecting rural populations.

Oil and mining concessions have been developed in the name of ending poverty in the country, yet there has been little to no investment in the development of the local rural communities affected by this extraction (Rudel, 1989). To the contrary, oil and mining projects pose a threat to the health and wellbeing of rural communities through forced exile, environmental contamination of water resources and deforestation (Vidal, 2016). While government leaders state that these projects can be carried out without environmental damage, mining environmental experts disagree (Vidal, 2016).

\subsection{Cinterandes Mobile Surgery Program:}

The Cinterandes Mobile Surgery Foundation is a non-governmental organization founded in 1990 by a former Ecuadorian Minister of Health and general surgeon, belated Dr. Edgar Rodas Andrade. Motivated by his recognition of limited surgical care access for people in rural and resource-limited settings, he formed the Cinterandes Foundation to address unmet surgical needs. Driven by a moral duty towards social equality, the Cinterandes team began providing intermittent surgical services in rural settings in

1990. The team traveled to primary level hospitals that lacked surgical capacity. While hospitals provided 
the surgical infrastructure, the Cinterandes team voluntarily provided the surgical workforce, supplies and surgical services.

Then, in 1994 the mobile surgical unit was incorporated into the Cinterandes mobile surgery program. This fully functional surgical unit is assembled on a 24 foot Isuzu truck. It is equipped with a preparation room which includes a changing area, washing station, small bathroom, autoclave and storage. This area connects to the operating theater which is $4.20 \mathrm{~m} \times 2.50 \mathrm{~m}$ (Shalabi et al., 2017). The operating room is fully equipped for general surgery procedures including laparoscopic surgery. Finally it is equipped with a hydraulics ramp which opens at the back of the operating room where patients exit the theater to be taken to immediate post-operative care outside the surgical unit (Figure 1).

Through the use of a mobile surgical unit, Cinterandes provides low risk general surgical care in urban, rural and remote communities to offer care to financially vulnerable patients. The mission of Cinterandes is to bring high quality, timely and safe surgical care to people who are most in need (Cinterandes, 2017). We hypothesized that mobile surgery may play a role in addressing possible barriers and delays confronted by rural populations, and sought to understand how Cinterandes impacts surgical care delivery in rural settings.

Overall, by understanding the perspectives of Cinterandes mobile surgical care providers, hospital providers, leaders and patients, we aimed to assess surgical care access in rural settings of Ecuador and understand the role that mobile surgery plays in addressing the surgical needs of rural populations. 
(a)
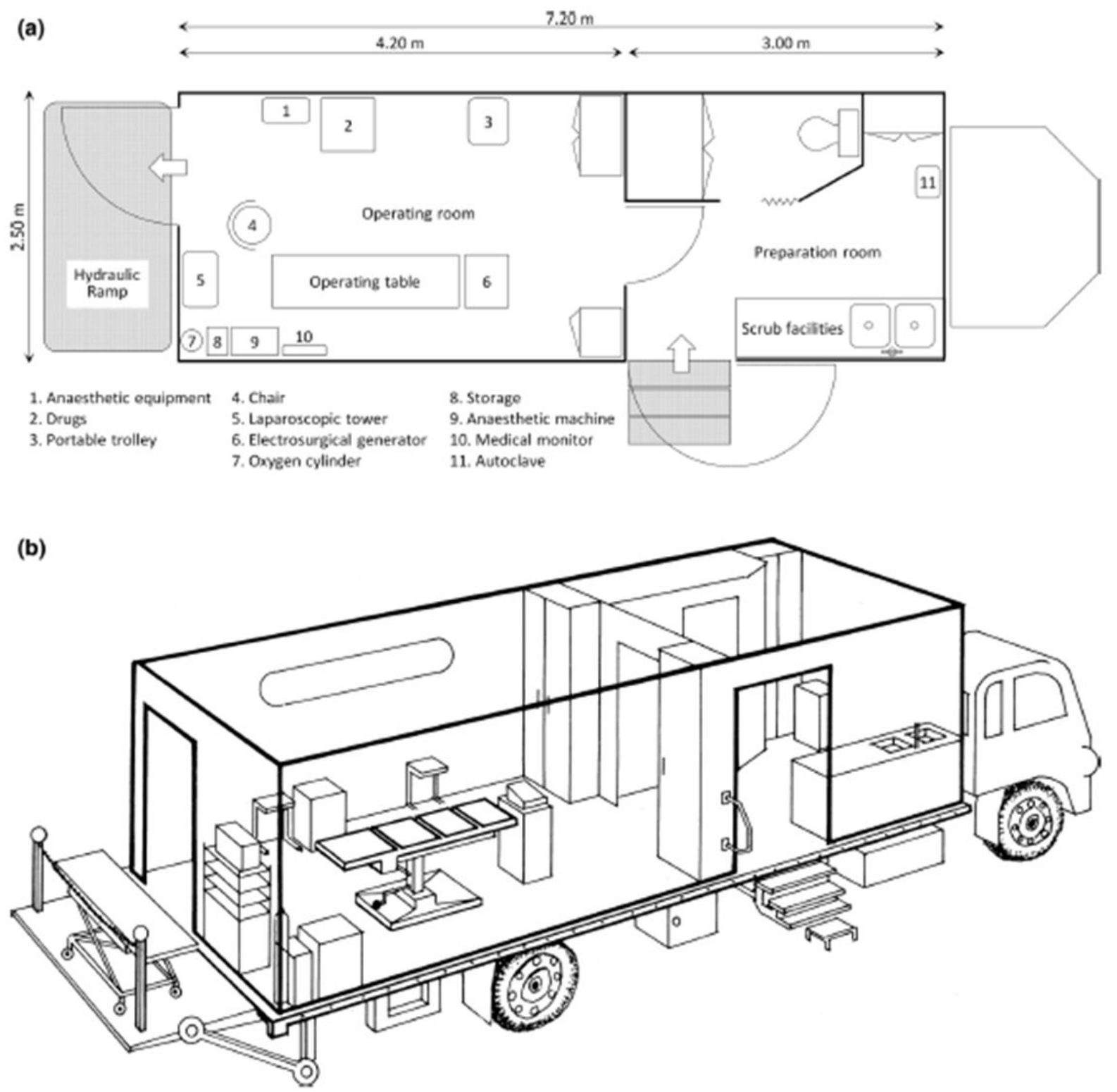

Figure 1. Cinterandes Mobile Surgical Unit Design (Shalabi et al., 2017) 


\section{METHODOLOGY}

\subsection{Study Design:}

This qualitative assessment employed an inductive, content analytic approach to document perspectives on access to surgery in rural Ecuador (Patton, 2015). We carried out multi-vocal semi-structured interviews. We interviewed 36 different informants including patients who have sought or were seeking care for a surgical condition from hospitals $(n=5)$, and the Cinterandes mobile surgery program $(n=9)$, we also interviewed a participant with a diagnosed surgical condition but not in care $(n=1)$, hospital healthcare workers $(n=7)$, Cinterandes healthcare workers $(n=7)$ and stakeholders from the community or healthcare settings $(n=7)$.

Semi-structured interviews were chosen to facilitate informants' ability to provide in-depth explanations about barriers, delays and facilitators. During the interview process, the researcher used probing of key information as a method to gain greater insight about informant's perspectives and experiences. The interviews were one to two hours in duration which gave participants ample opportunity to reflect on the topics being studied and allowed the researcher the ability to verify the validity of information by confirming answer's accuracy on multiple occasions throughout the interview.

\subsection{Ethics statement:}

This study was approved by the ethics review board at the Office of Human Research Administration (OHRA) at Harvard University, Boston, USA \& Hospital Homero Castanier Ethics Committee, Azogues, Ecuador. All informants consented to participate in written form.

\subsection{Study Setting:}

This study took place across three different regions in Ecuador, west coast, southern Andean highlands and southeastern Amazon which included Santa Elena, Azuay, Cañar, Morona-Santiago provinces. Five 
towns within these provinces were included because of their significant rural populations and because Cinterandes provided mobile surgical services in these communities.

Table 1: Total and Rural Populations by Province

\begin{tabular}{|l|l|l|}
\hline Province & Total Population & Rural Population (\%) \\
\hline Azuay & 712,127 & $331,682(47 \%)$ \\
\hline Cañar' & 225,184 & $130,659(58 \%)$ \\
\hline Morona-Santiago & 147,940 & $98,281(66 \%)$ \\
\hline Santa Elena & 308,693 & $104,076(33 \%)$ \\
\hline
\end{tabular}

(INEC, 2010)

Specific town names are kept confidential to protect the privacy of informants. The town within Santa Elena province is a rural coastal town of approximately 6,000 inhabitants. Their main source of income is fishing. It is important to note that during the time of data collection, fishermen were prohibited from fishing activities due to environmental restrictions which prohibit fishing during certain months to protect the ecosystem. This affects the financial stability of coastal inhabitants and it should be considered when understanding the importance of optimizing surgical care access.

In Cañar and Azuay provinces, the towns were nestled in the Andes Mountains. Informants were from remote, rural or rural-partially-urbanized environments. In the remote settings, informants were from communities high in the upper parts mountain. For rural settings, the participants were from towns outside cities and for the rural-urbanized environments, participants were from micro-rural environments within the urban setting. Rural residents commonly practiced subsistence farming, or manufacturing hats made of paja toquilla (Panama straw hats), or worked/studied in the urban setting. 
In Morona Santiago province, we included informants from a remote community near the Cordillera del Condor neighboring the southeastern border with Peru. This community had about one hundred and fifty adult inhabitants. Most inhabitants were subsistence farmers or worked as miners in the nearby copper mining company.

\subsection{Inclusion Criteria:}

We included participants who were at least eighteen years of age or older.

\subsection{Exclusion Criteria:}

We excluded vulnerable populations such as children and individuals with mental illness or mental incapacity.

\subsection{Data Collection}

Between February and March, 2017 we carried out 36 in-depth semi-structured interviews in Spanish with adult participants. These interviews ranged from one to two hours in duration and were conducted by one research team member, Dr. Vega. Interviews were audio-recorded with participant permission. The interviews were guided by the set of topics outlined in the attached interview guides (appendix 1-4). Note, that in our research protocol we also included interview guides and research tools in Kichwa language, to include Kichwa participants who were non-Spanish speakers. Although, we did not use these in our interviews because all our informants spoke Spanish, we considered this step important because it was possible to we would encounter non-Spanish speakers. We elicited in-depth answers to these questions by following up with probes tailored to each participant in order to elicit rich data on access to surgical care and mobile surgery.

Patient interviews took place in a private setting such as a private room in a clinic, hospital or community center or in the patient's home. The interview focused on identifying and understanding 
barriers, delays and facilitators about surgical care access for rural patients. The interview guide covered the following key areas: patient's surgical condition and its impact on social and personal life; the surgical care seeking experience; identification and timing for the three surgical delays; outcome and satisfaction with service; perceptions about effectiveness of surgical care system; perceptions on how the surgical care system may be optimized; and the social and emotional implications of confronting a surgical illness. In addition to what is mentioned above, we interviewed Cinterandes patients to understand their experience receiving mobile surgical care and how this compared to experiences in the hospital.

Interviews with healthcare workers and leaders focused on the following key themes: their experience serving rural populations; perceptions about barriers, delays and facilitators and how these may affect delivery of surgical care; opinions about the overall surgical care system; and how it may be optimized to improve care for rural patients.

Cinterandes healthcare workers interviews focused on the role of mobile surgery; how it works in the context of the rural setting and the reasons behind their sustainability and success. We sought to understand barriers in conducting the mobile surgical program, and barriers and delays rural patients experience in seeking care. Moreover, informants provided their perceptions on optimizing the surgical care system for rural patients and collaboration with the government.

\subsection{Data Preparation and Analysis:}

Audio recorded interviews in Spanish were directly transcribed in Spanish by hired transcribers. We completed a read-through of the entire data set. Using Dedoose data analysis software, we open coded a sub-set of interviews to identify themes for the purposes of developing an initial codebook. This codebook was piloted and revised, and the final codebook was used to direct code the entire dataset. 
The resulting coded data was then analyzed inductively to form initial conceptual categories. These initial conceptual categories were named, defined, and illustrated using excerpts from the interviews. These categories were reviewed, refined, and elaborated through an iterative process that was marked by continually revisiting the data to incorporate relevant text. This iterative process was undertaken to add explanatory heft to our findings, and to ensure the accuracy of recurring themes obtained. This analytical process resulted in the identification of twelve themes including nine barriers and delays and three facilitators to surgical care access.

\section{RESULTS}

\subsection{Barriers and Delays:}

\section{1) Unfamiliarity with hospitals, doctors and the urban setting create fear and dissuade rural patients from going to hospitals}

Patients and healthcare providers recognized that rural patients consider the process of seeking care at urban hospitals to be an intimidating experience. Cities and hospitals are perceived as hostile environments by some rural patients. Informants reported that rural patients are prone to humiliation and danger in the urban environment which causes fear and reluctance to seek care in city hospitals.

"The patient from the rural setting is a very special patient. The city intimidates the patient, the city is like a monster for them because they are humiliated and mistreated many times, and abused many times, other times they are robbed, so the patient is afraid to come to the city and to the hospital."

(City Hospital Surgeon)

The hospital itself is also perceived as an unfamiliar environment, and navigating the hospital system can be a confusing experience for the rural patient.

"He [the rural patient] comes to the hospital and he is a lost patient. He does not know where to start, he does not know who to approach, he does not know who can provide help."

(Hospital and Cinterandes Surgeon) 
Patients were also frightened of the surgical procedure. Many were not informed about what surgery entailed, and their lack of familiarity with the process led to significant fear. A hospital patient from the Andes explained:

"I had never been operated, so I was very nervous, I don't know why, but it was nerve wrecking. I do not know what happens during the surgery, they had to take out my appendix, many things come to my mind."

(Hospital patient Andes)

The foreign appearance of a physician and the unfamiliarity of health centers created for them a sense of distrust. A patient from the Amazon who received surgical care at a hospital narrated from her personal experience:

"The truth is that I did not have trust because I had never met doctors that do surgery. Everything was fear, everything was fear, everything was strange, what will happen to me? I will die... When you have never been sick, and you go to a clinic, it is a different. It is as if I took you to the dense forest and I leave you there. It is the same for us. For the first time we see a doctor in white, with gloves, and to see all those things, it is scary."

(Hospital patient)

Multiple healthcare providers also recognize that a number of rural patients were afraid standard procedures such as removing their clothes during the physical exam. A nurse who has worked extensively with rural patients explained that the removal of clothes was perceived by some as a threat to their safety:

"They have not seen doctors and they are afraid to remove their clothes, they do not remove their clothes. I think they have a lot of fear of doctors, what will he do to me? What is he going to see on me? They are afraid doctors will cause them more pain." $\quad$ (Cinterandes nurse)

Other standard procedures such as informed consent are also unfamiliar to rural patients. This can lead to misunderstandings and misinterpretations about surgical procedures and outcomes. One participant shared the experience of a mother who had brought her daughter from their rural community to an urban public hospital for a surgical procedure. The mother was asked to sign a waiver giving the physicians permission to proceed. The waiver contained standardized language about the risk of death inherent in exposure to anesthesia and surgical care. The mother was unfamiliar with this routinized process of consent, and the legal language caused her such alarm that she decided to stop her daughter's surgery. She elected to take 
her daughter instead to a private hospital, where she believed she would not incur such risks. The family incurred significant debt as a result of transferring their daughter to a private hospital for her surgical needs.

\section{2) The Responsibility to the Family Unit}

In speaking with patients, physicians and healthcare leaders we learn that the preservation of the family unit is paramount in the process of care-seeking for the rural patient. The burden of providing for the family's well-being played a role in patients' decisions about whether and when to seek surgical care. Family considerations weighed particularly heavy on heads of households, who maintained that the wellbeing of the family took precedence over their own physical health. Patients hesitated to incur costs associated with surgical care and they worried about lost income and the effects of work left undone within the home. The following example illustrates how patients elected to put up with the effects of surgical disease, rather than pursue a surgery that would compromise the family as a whole:

"I went to the doctor and he told me I need surgery. I told my wife: No, if I get operated, who will work and help with the children that are studying? Who will help you when you need to take the bus alone if I am in bed? So I said, I will tolerate [the illness] and when I want to, I will decide to operate. And that's how I kept tolerating and putting up [the illness]."

(Cinterandes patient)

In effort to maintain the financial stability of the family unit, it is not uncommon for the rural patient to postpone surgical care for very long periods of time. The individual patient assumes pain and other physical symptoms so that the family may be spared the immediate financial hardship of seeking surgical care. Unfortunately, chronic postponement of surgery can lead to become severely incapacitated, and ultimately disrupt family's financial stability. One Cinterandes physician explains the long-term financial hardship of postponing surgical care:

"In rural settings, we have seen hernias that are 20 or 30 years old. Patients have not sought care or because of the various circumstances, they were diagnosed but they stopped seeking care. The reality is that they will reach a point when a patient will not be able to work because of the 
pain and that will have enormous consequences in economies of these families.

(Cinterandes physician)

Families often travel together when a family member requires surgery. While someone may be accompanied by a single family-member, it is not unusual for entire families to travel together with the ill rural patient:

"Generally the rural patient does not travel alone, but with one or various family members, that is an idiosyncrasy of our people. When a patient has health problems, many family members go with him."

(Cinterandes anesthesiologist)

When a rural patient is unable to avoid leaving his rural community to seek surgical care at a city hospital and is unable to afford the transportation for the family to accompany him, families will take extreme measures to make the trip as a family unit. A patient narrated how his wife, children and family members travelled from his rural town three hours away by bus. They were living in poverty, and did not have money to pay for the one-way fare to the city. The patient's wife went to the town's church to beg for money. The wife and family members made it to the hospital, but they had no additional money for food and lodging. Other family members begged for money at the hospital to return home, but the wife - who was pregnant - decided to stay in order to accompany her husband. With no place to stay, the woman slept in the hospital lobby, on the cold ceramic floor. Multiple healthcare providers reported that it is common for rural families make significant sacrifices in order to stay close to a hospitalized family member.

\section{3) Distrust in the Public Healthcare System}

Rural patients' narratives about the formal health system often intersected with broader perceptions about the state's overall treatment of indigenous peoples. There are historical antecedents of mistrust in the public healthcare system. Patients are keenly aware of the state's long history of incursion on the rights of ethnic groups, and the role that health care has played as a vehicle for persecuting these communities. 
Longstanding mistrust in the state's intentions correlates to a mistrust in the state's recent efforts to extend medical care into remote communities. One patient from the Amazon explained:

\begin{abstract}
"This generates lack of trust, here in the community we say that all that the government sends, like food and all the medications, like vaccines, contraceptives, all the people here consider that it is to exterminate the indigenous, that is the tendency here. We have that tendency because the government is always fighting with the indigenous. We are not going to give that [food or medications] to our children, because we have had intoxications at Pastaza province, there have been children intoxicated with the food given at schools... So this generates a negative expectation, and the community will not accept this, even if the doctor from the government sends the medication, we do not trust them. And you know what, the Shuar people even say that the medications that are sent is so that the Shuar will not reproduce, so that the Shuar will be totally vanished...." (Amazon hospital patient)
\end{abstract}

Patients and community leaders reported that the lack of physicians in indigenous communities amounts to abandonment by the state. One leader notes that this abandonment is glossed by the state's narrative about allowing ethnic groups to cultivate their own identity and pursue their own way of life:

"For us here among the indigenous, there are no doctors. The Ecuadorian state does not support the indigenous. They have always told us: that we are deceivers, that's how the indigenous are, we were always labeled that way. But the truth is that we are good indigenous. We should have Shuar doctors, but we have been abandoned by the Ecuadorian state, we do not have[Shuar] people that become specialists, doctors...The government has abandoned us, they let us live however we are able to live. Although they [the government officials] speak of Buen Vivir (the national plan of Good Living), but good living is to cultivate many cultures, and not only the Shuar, but many indigenous cultures. Every group should have good doctors, all indigenous should have good doctors, but we have not achieved that, because we have had the barrier of the state... We have always been treated as an indigenous population that is poor and that it should always remain poor."

(Community leader Amazon)

These comments speak to deep, long-standing mistrust of government intentions upon which current interactions with the public healthcare are mapped. Family planning measures are viewed as particularly suspicious:

"Many people, the indigenous, many women have implants. We must talk a lot about this; women sometimes gain a lot of weight, they become obese, others become very skinny. So people think that the government is sending a disease, a poison, for the indigenous will fall.

(Female Hospital patient) 
Mistrust of the public healthcare system also stems from the perception that the healthcare services provided by the state have long been considered sub-optimal. For decades, the public healthcare system was underfunded and unstable, creating longstanding distrust. While recent changes in the public health care system have made significant strides in increasing the quality of care at public facilities, many patients in rural areas maintain a strong association between the public system and poor quality care. One surgeon explains:

"In the past, the hospitals were of terrible quality, there was great distrust, so people would look for any way possible to seek services at private centers, even if they had to loose ownership of their goods. As consequence private practices grew while the public sector continued to lose quality. More time was spent on strikes rather than providing services. But now with the change in government, with greater responsibility, more has been invested in health."

(Hospital surgeon)

These longstanding doubts about the quality of health care available to rural patients often mingled with rumors from families and friends to create significant fears about seeking surgery within the public system. One patient explained that his wife's experience of pain during her surgical procedure made him reluctant to pursue care for his own surgical disease:

"When my wife returned home from surgery (from a hospital), she was in pain and she told me 'in the cut, [the doctor] made me feel the knife, strongly, the anesthesia did not numb me much.' That's when I realized that the anesthesia was not good."

(Hospital Patient)

The presence of surgical scars was also an important factor that sowed mistrust in surgical procedures. Seeing or hearing of disfiguring surgical scars among rural community members create great distrust which keep people from seeking surgical care from public hospitals. Two rural patients explain how family members' scars were a strong indicator of the lack of quality of surgical care:

"When I went to see [my godson] after the [hernia] operation, the cut was so ugly. He still has a thread sticking out, and it has not yet been removed...it has been seven years since the operation and [the thread] is still there... That is why I do not like to go to the hospitals, it is not that I have something against doctors from public healthcare services. It is because they are not doing things right."

(Patient Amazon)

"I think they are not very well, not very well prepared to be doing surgery. Sometimes these are doctors who are practicing, and they do whatever they can...I have my sister who got surgery [at 
the hospital] and she has huge scars, that's why I do not think the surgeries they do are good." (Cinterandes Patient)

Doctor-patient interactions also influenced views on quality of care. Some public hospital rural patients were very satisfied with how healthcare providers and staff treated them, but other patients reported being mistreated by healthcare providers. Multiple patient informants mentioned that they feared mistreatment at the hands of healthcare providers. Negative doctor-patient interactions created a mistrust of doctors. A patient from the rural Amazon narrates about a callous interaction with his physician:

'One time I was sick, the doctor said: 'Resist the pain!' But [I said] who can tolerate the pain of a snake? No one can resist it! He said, that doctor said!: 'Why? Don't you know what pain is?' (patient expressed resentful demeanor) Well! And if we can give him that pain, that doctor would probably complain ayyy! And would scream! But sometimes they don't feel what a human suffers or feels."

(Patient Amazon)

\section{4) Health System Inefficiencies}

In spite of state's investment in the public sector and commitment to improve care delivery, multiple informants unveiled health system inefficiencies in the care seeking process. Patients and surgeons alike report how different delays and missteps have made it difficult for patients to enter the public surgical care process. A rural patient from a remote Andean community, who for a year was unsuccessful in her attempts to enter the referral process to obtain surgical care stated:

"I went to the health center. I got there and I told them I want an appointment because I have a big ball [referring to a large inguinal hernia]. I was told, 'no, no no, now we only give appointments by telephone, you need to call later or tomorrow and we will give you a date for your appointment, but this will delay about a month,' they told me...I called using a cellular phone that I borrowed from my neighbor. I said, you know what; I need an appointment to get examined. They told me 'no'."

(Patient from remote Andean community)

Healthcare providers attribute the difficulties of obtaining an appointment to the high demand for surgical care services. A surgeon from the public system states:

"In the public system, we must handle lists... I would have to give an appointment to patients in 2, 3, 4 or even 6 months. I did this reluctantly because the reality was that these patients really 
needed surgery but I was unable to schedule them earlier because the list was full."

(Hospital Surgeon)

Multiple healthcare providers considered that the appointment system was not well suited to serve rural patients effectively. All patients are required to obtain initial appointments via telephone or internet systems. Another surgeon depicted how inadequate this process was for rural patients because they were often unfamiliar with how to use these forms of communication, and therefore maybe unable to enter the healthcare process:

"Surgeries that are non-emergency must go through the call center. People must call to get an appointment, but people are not yet very familiar with making a phone call. This system should supposedly facilitate things, but not all people know how to use or even have access to internet, and it is even worse in rural areas. So here, in thinking of how to improve the healthcare system, we [healthcare providers] have confused things. I think the call center is okay because people are familiar with a phone and they can use it, but the internet, I don't think so. I have seen it is a problem for patients from rural areas."

(Surgical Leader)

In addition, healthcare providers noted a discrepancy with the design of the referral system and its actual practice. Surgical care providers acknowledge that the referral system is sometimes disorganized and slow:

"In the hospital, when it is necessary to transfer patients to other health centers, with the integrative public healthcare network, of course the idea is perfect, but in practice the integrative public healthcare network is deficient in many ways, that is, it does not always work in an expedited manner, nor is it diligent in the way it functions. If the public system would make [processes] function in a coordinated and cohesive way, it would be marvelous."

(Hospital Surgeon)

Surgical providers also reported that another reason for the ineffectiveness of the referral process is that some primary health centers lack the ability to accurately diagnose surgical patients. As a result, patients are referred to hospitals to obtain a diagnosis. One healthcare provider explained that sometimes basic diagnostic equipment is lacking at primary healthcare facilities; others questioned physicians' abilities to clinically recognize surgical conditions. Another surgical provider explicitly linked primary level diagnostics to the effectiveness of the referral system as a whole: 
"By increasing the capacity to diagnose at the primary health care centers, many of the referrals should be avoided. It is the lack of capacity to diagnose at the primary health centers that create referral problems which increase the demand [of services] even more, and this should not happen. Those that arrive to the hospital should be those that really need to be there."

(Cinterandes surgical care provider)

According to another surgeon, other contributors to the slow-moving referral process are an imbalance of referrals between hospitals and the high populations oversaturating facilities in certain regions. A surgeon states how he perceives this imbalance:

"The hospitals that should send patients to us should be from [2 hospitals], but currently we receive patients from everywhere and of all kinds [of cases] from 18 hospitals. We even receive [transfers] from provinces that do not correspond to us...the hospital in Guayas has collapsed...Guayas serves a large province with large towns, so my impression is that the number of beds available is not sufficient for the number of people in the population. Guayaquil [main city within Guayas province] alone has 3 million inhabitants."

(Surgical Leader)

Due to the inability to enter the surgical care process or navigate the referral system, patients often find themselves going back and forth from health clinics to emergency rooms in their attempts to seek surgical care. Patient's unsuccessful attempts at advancing the surgical care-seeking process drives patients to become disengaged from care seeking, as explained by an anesthesiologist:

"There are many problems [in referral system], the patient needs to bounce from one place to another, and that has a cost. Even if exams are covered [financially], but there is the cost for his transport, his time, he becomes bothered that his problem is not being resolved. This makes our system slow and difficult for the patient. Over time, we commonly see that the patient will abandon care-seeking for his disease. And if the problem is not too urgent and it does not bother him, he will abandon care-seeking because of lack of time and discouragement."

(Cinterandes anesthesiologist)

\section{5) Displacement of Decision-making Power}

During the last ten years, the Ecuadorian healthcare system has undergone significant structural changes introduced by former President Rafael Correa's Alianza País (Country Alliance) political party. Under the new model of administration, the public health system became more centralized. Local healthcare facilities became part of larger administrative institutions, called zonal administrations. The country was 
divided into nine health system zones rendering each zonal office political and decision power over their provinces and the healthcare institutions within those provinces.

According to healthcare workers and providers, centralization has led to the shifting of decision making power from local health centers to zonal and federal administrations. The central government's new strict policies mandate that surgeons must be hired for exactly eight hours per day. Surgical providers have noted that this eight-hour timetable is not amenable to providing 24 hour surgical care within their facility. Many surgeons working at primary level hospitals arrive to work between seven and eight in the morning and leave at four or five in the afternoon. Outside of these hours of operation, then, no surgical care is available:

"At this time, due to a disposition by the Ministry of Health, there is no possibility to hire personnel but under certain conditions. Such as the schedule, it must be 8 hours. The Ministry does not allow a person to be hired unless it is for 8 hours. Therefore I think that at some point this needs to be revised...I think that immovable measures are not good in an administration."

(Hospital surgeon)

This eight-hour system is reported to be problematic because surgeons are not available to be "on call" outside of these standardized shifts at many of these facilities:

"The problems should not be seen [when you implement new] forms of administration, for example there are no specialists throughout the day? To cover for emergencies, surgical emergencies, gynecology-obstetric emergencies...there could be problems when there aren't specialists at night. At the [...] hospital and at [...] hospitals, there are no specialists at night to do on-call."

(Hospital surgeon)

According to the centralized system, to make surgical services available outside working hours a patient must be transferred to a hospital where after-hours care is available. In some cases, this could involve subjecting an extremely ill patient with an emergency condition to travel by ambulance for several hours. A hospital surgeon explains that under this system it is possible that a patient with an acute surgical 
condition like appendicitis would need to travel for several hours before arriving to the nearest functional hospital with surgical capacity:

"During daytime working hours, that is up to around 4 or 5pm, the surgeon leaves after that, the surgeon will not come to operate. So if the patient has appendicitis for example, an abdominal trauma due to a car accident, that patient's problem could have been resolved at the site where the patient is, territorially speaking. [But] these patients need to be transferred in dire conditions. From the hospital [that refers to us] to here by ambulance is about 3 to 3:30 hours in the best of cases, but this could be terribly unfavorable for the patient." $\quad$ (Hospital surgeon)

Budget decisions are now controlled by the central administration, so local hospital leaders are not able to nimbly adapt their budgets to the specific needs of their hospital. This is particularly challenging for planning and executing supply procurement. Surgical care providers noted that following the institution of the new centralized administrative system, they are wary that supply chain interruptions may occur. They perceive that investment in supplies has been notably uneven across hospitals, with preference given to larger city hospitals:

"Power was taken away from our province, meaning that they [the other province? take away from us! Before, we had our own health administration. Our hospital was decentralized, not concentrated. So what we did is that we ordered things and paperwork went through immediately because things arrived quickly, this hospital always worked well. Now the [large city outside our province] grabs a hold of the whole zone, and we are at the mercy of [that city]. I do not think that's how it should be done... We should have our own processes."

(Surgical care provider)

With large city hospitals receiving the lions' share of investments, primary level hospital providers feel that they are underserved in this centralized system, and thus have limited ability to provide care. They perceive that their needs are often overshadowed by the needs of larger hospitals.

"I think I feel, and I think many people feel...we feel relegated to second place because [the larger city] absorbs more. But before it was not like that, because before we had our own processes, our own administration here at our province. Over there (meaning the larger city) it is bigger and they also [they] have their mentality for [their city] and yes...they give us less service."

(Surgical care provider) 


\section{6) Strong Regulations on Non-Governmental Organizations:}

As previously mentioned, political and social structural changes have occurred in the last ten years following the neoliberal era. This included modification of the constitution and implementation of new laws surrounding healthcare and non-governmental organizations. On June $4^{\text {th }}, 2013$ executive order \#16 was signed to require all non-governmental organizations to abide to strict government regulations. While the government stated that this was simply done to unify the registration of NGOs in a central system (Puente, 2017), NGOs stated that this decree was used as a strategy to criminalize and control people who counteract the government (Ecuador Libre Red, 2013). Many NGOs were closed down on the basis of engagement with partisan activity, interference with public policy or threatening internal security

(Davalos, 2015). For example, Fundación Pachamama a major organization that defended indigenous and environmental rights, was closed down unexpectedly because the government alleged that it was involved in verbal and physical aggression against Chilean representative of oil companies during a manifestation and that the foundation had deviated from their aims and objectives (Constante, 2013). Fundación Pachamama denied the claim, and members considered this was a violation of their right to protest.

Healthcare providers and community leaders view that the government wants to be the main operator to control healthcare delivery in the country. Efforts of non-governmental organizations (NGOs) to improve healthcare for rural populations may be interpreted as intrusions against the government. It was reported by various informants that the government may take action to neutralize people or institutions whose activities may be inconsistent with the state's objectives:

"They [the government] will try to do everything, only them, but it gets complicated for them. They make things difficult. If you are doing something [for society], they may come and suddenly they may block you. It is as if what they want, is for them to be the only ones taking care of healthcare."

(Healthcare Community leader)

Healthcare workers perceived that the government believes that if an idea or effort does not originate from the government, it may be considered bad: 
"In the last 10 years, what is not from the government, it is not good. Or if the idea is not from the government then it is not good"

(Surgical leader)

Moreover, the collaboration between private NGOs and the government is seen as unlikely because multiple informants viewed the government as an inflexible and insular institution, which may not leave opportunity for collaboration:

"Interviewer: Can the government collaborate with private NGO healthcare institutions? Informant: The government is totalitarian, they want to do everything, that is the problem"

(Community leader)

Such views and perceptions about the government are a product of witnessing healthcare NGOs close down in recent years. For example, a surgeon explained that despite healthcare investments, other government actions have impeded health care delivery to the most vulnerable. He stated that although the shuttering of many NGOs was justified because the government identified that some institutions were actually making a profit; he regretfully notes that other institutions which provided "spectacular" services for vulnerable rural populations were also closed down.

"There are great things that the government has done, but there have also been bad things, such as trying to make NGOs disappear...[a] hospital which was technologically advanced in the middle of the Amazon where there was nothing, the hospital disappeared."

(Hospital Surgeon)

The closure of NGOs is perceived as a persecutory action on behalf of the state on private healthcare institutions. After the closure of healthcare NGOs, it was also reported that patient populations were not given replacement for the healthcare services. In other words, it was perceived that patients were abandoned:

"I worked for a foundation that was dedicated to work with vulnerable people in the city of Cuenca, it served alcoholics, homeless, prostitutes, but sadly because of politics, and laws, there was a persecution against private organizations, so this group had to close, and no one continued this type of work"

(Cinterandes physician)

The close down of NGOs has been a concern for the Cinterandes Foundation. The team reports that in recent years, the program has experienced difficulties when trying to provide surgical care in some communities. Despite proper planning and acquisition of formal approvals prior to travelling to a 
community to provide surgical services, some surgical missions have been forced to cancel because the local state leadership may be opposed:

"Sometimes we cannot work in certain places because provincial health leaders may be opposed so that is a barrier...Not too long ago, we had to cancel a surgical mission on our mobile unit because of politics. So at this time we do not know what could happen."

(Cinterandes surgical care provider)

Despite the difficulties encountered, the Cinterandes mobile surgery team has a positive outlook into the future and believes that collaboration with the government can be strengthened to achieve their common goal of improving the health of poverty-stricken patients:

"We hope that in the future there could be more collaboration [with the government] so that emphasis will be placed on the health of patients, who need help, especially those that are poor and need the services to be free, which is what we do."

(Cinterandes anesthesiologist)

In order to achieve a stronger collaboration with the Ministry of Health, the Cinterandes team calls for opportunities for dialogue to share knowledge and to jointly strategize how surgical care may be improved:

"For two institutions to collaborate, both need to be open, to share knowledge, to learn from one another, from the institutions that can participate in certain projects to improve the healthcare system...I think the main [keys] are organization and communication. It would be vital for the healthcare system to be integrative, so that we can collaborate with the Ministry"

(Cinterandes Physician)

\section{7) Unique Remoteness of the Amazon}

People reported that access to surgical care is particularly difficult in the Amazon region. Its climate and geography create unique challenges for residents attempting to access surgical care at hospitals in larger towns and cities. Some communities can be accessed by vehicle, while other more remote communities can only be reached by air. Residents of these remote communities do not have access to this kind of transportation, and must therefore attempt the journey on foot. The seasonal climate conditions can make this journey treacherous - especially for a patient who is in acute need of surgical care. One patient from a remote Amazon town explains how lack of transportation limits access to surgical care for members of his community: 
"Here in the Amazon, the geography is diverse. Because of the rain and our climate, rivers grow. We do not have vehicles or access to helicopters or airplanes, therefore all is done by foot. That hinders communities in these places... There are people who do not have access."

(Non-treated surgical patient)

Community leaders were aware of the lengthy trajectories that patients must travel in order to attempt to access surgical care. The extreme remoteness of Amazon communities along the Ecuadorian and Peruvian border created particular challenges for patients. Their homes were located deep within the forest, and they had to travel for several days in order to reach a health center:

"[In South-Eastern Ecuador] Nangariza, is an area deep in the frontier with Peru...If they walk for example from there to here, it is one day of travel. And then, if they take a car, they will arrive here on the second day. So it would take them two days to arrive."

(Community healthcare leader Amazon)

Another leader illustrates how lack of infrastructure created physically challenging journeys, with surgical patients having to traverse rivers via hanging bridges:

"A town with a significant population size on the other side of the Zamora River, cars cannot cross to the community because, the only way to access the community is by crossing over by foot via a hanging bridge."

(Healthcare community leader)

People in the Amazon were often willing to travel long distances in order to receive surgical care. In an effort to address the remoteness of the Amazon, the Cinterandes Foundation extended their outreach efforts by creating a mobile surgery program on a boat to provide surgeries along an Amazonian river. Surgeons had already travelled great distances to serve these remote communities along the river, and they were surprised to encounter patients who had come from even greater distances, traversing national borders and vast jungle terrain for days just to reach the already remotely parked surgical boat:

"Curiously, we operated on a lot of people, more from Peru who would cross the border. It was interesting and sad when we asked how long it took them to arrive to our mobile [surgical] unit, and they would tell us three days. For us [the team] it was far to travel for one day, but three days! It was very sad. And [they] would come by land, through the river, and went through so many things in order to receive a surgery."

(Cinterandes Surgeon) 


\section{8) Lack of Supplies Negatively Impacts the Delivery of Surgical Care}

Despite acknowledgement that the healthcare system is designed to provide high quality services, it was reported that intermittent lack of availability of medical and surgical supplies may affect delivery of healthcare services. Informants revealed that the supply chain process is dynamic and requires constant monitoring to ensure adequate delivery of supplies and services. Any interruption in the steps involved would mean imminent failure in the timely delivery of supplies, which can negatively affect delivery of care. One supply chain specialist explains:

"One must be alert all the time, monitoring, there cannot be one day without comprehensive monitoring, that all purchases were done, that goods arrive to storage, proper entrance of inventory, correct orders from pharmacy department to the storage department. Because, there can be medications that have arrived to storage, but they are not yet [available] in pharmacy. This is a job that works in cycles, where if one part fails, all of it fails."

(Hospital Supply Chain Specialist)

Healthcare providers and healthcare workers at the forefront of service delivery explain why shortages of supplies occasionally occur. Informants attributed stock-outs to problems of delays at the national-level ordering system. Late ordering and insufficient funds hamper the national ordering system, and negatively impact the timely delivery of supplies:

"The most important issue is administrative. In our country we have a purchasing system. It is a national system and no one can work outside of it. In that system, public purchases have problems, some more dire than others. For example, one problem is the time that it takes for a product to go up to auction and for it to finish the process until the medication arrive here, it may take a month. Ideally, the process should be done a month prior to medication stock-oust, but it does not always occur that way. That is the administrative problem. And the other problem is economic, that is, we have the need, but we don't have money at that moment."

(Hospital surgeon)

According to a hospital supply chain specialist, stock-outs also occur because some institutions may not adhere to the established processes: 
"Sometimes we run into the situation, it happens sometimes, that we do not have a medication available because the provider, who should make the medication available to us, does not abide to the [ordering] processes."

(Hospital supply chain specialist)

In addition, this specialist also explained that suppliers themselves may experience stock-outs because of high demands, creating region-wide shortages of even the most basic supplies, such as saline solution:

"The provider that sends us sodium chloride [solution], this provider many times because of the high demand, it runs out of stock so it is unable to provide this medication to us, so our stocks get broken as well"

(Hospital Supply Chain Specialist)

Others note that supply chain interruptions may also occur at the local level, within a hospital. For example, a hospital leader stated errors in supply registries within the storage department of his hospital created record-keeping problems that impacted the availability of supplies for patients:

"Sometimes the processes or administrative circumstances do not, do not allow us to do that [prevent stock-outs]. For example, the storage department, they should have a registry of everything. Sometimes, I do not know why, sometimes there is a gap in this, and it doesn't allow us to have a good count."

(Hospital leader)

Supply shortages directly affect surgical care delivery. In the most serious cases, surgeries have to be suspended because hospitals do not have appropriate surgical materials:

"Sometimes it's a matter of supplies; they are not available 100\% of the time because of budget issues. Sometimes we lack the supplies and we have to stop surgeries because of this situation. We do not have some things available, yet for the most part we try to resolve things."

(Hospital surgical nurse)

When patients confront situations of supply or service shortages, they are faced with the choice of stopping care, or assuming financial responsibility for basic surgical supplies. A surgical care provider explains this shift of responsibility:

"For example if a patient has a wound, many times they do not have sutures. The family of the patient is sent to buy sutures, syringes, and all that is necessary, because there is none available. So now things are difficult at the hospital. It is not good. I know that when there is lack of 
medications for a person who had surgery, sometimes they have to send the family member to purchase them after the surgery. One may say, I have pain, and there is nothing [meaning supplies or medications], none, not even the syringe."

(Surgical care provider)

Families are often required to step in and compensate for problems in the supply chain. They are crucial in environments where stock-outs and shortages create delays in diagnoses and surgical procedures. Patients who do not have accompanying family members are therefore particularly vulnerable to the effects of stock-outs:

"For people who come alone and who are not able to purchase the medications, I think things would be complicated for them. We must take into consideration health. The hospital should have greater quantity of medications, more availability. We must think of those people who do not have anyone. This makes me sad because there are people who come alone to the hospital without any family members."

(Hospital patient)

Stock-outs serve to erode patient perceptions of quality of care. Patients that received surgical care at hospitals, and those that sought care at public health clinics, expressed concern over the availability of medications at healthcare facilities. Informants reported that medications were often out of stock or, when available, choices were often limited.

"[Regarding] Medications, I cannot say things are good, because they do not have variety, there is lack. I would like for that to be available at the health centers, for everything to be good, to have enough medication supplies, so that there is enough for everyone. That's what is lacking."

(Hospital patient)

\section{9) The Conflict Between Assumptions and Practices About Rural Patient's Use of Traditional Medicine}

Participants reported conflicting perceptions about rural patients' use of traditional medicine, and its impact on the timely delivery of surgical care. While surgical providers were quick to point to traditional medicine a source of delays in surgical care, patients and traditional healers explained that traditional medicine was incompatible with surgical disease, and did not factor into surgical delays. 
Surgical providers often perceived rural patient's use of traditional medicine as the outcome of patients' presumed strong connection to their cultural practices. Their "attachment" to this cultural practice was viewed as an impediment to seeking timely surgical care from a physician. The following excerpt illustrates:

"I think that they do not seek first a physician. People in rural areas are strongly attached to alternative medicine. So what they do when there is pain, is that they do not go to a doctor as first choice, but they go to a shaman or to the oldest member of the family, they know which infusions to give to them. They first try to solve their problems with ancestral medicine."

$$
\text { (Hospital Nurse) }
$$

Providers' assumptions about rural patients' use of traditional medicine places the responsibility of surgical delays squarely on the care-seeking behavior of their patients:

"The majority of [rural] cases, they come complicated because they were trying other types of medicines. So when they see the illness does not resolve with a simple infusion or a massage, as they are accustomed to, the illness gets complicated. Let's say the appendix; first they [the patients] drink teas, then something else. It may help them, but later they will come with a perforated appendix, with peritonitis because their first choice was not the doctor, but was their ancestral medicine."

(Hospital nurse)

In contrast, rural patients noted that while some illnesses can be alleviated with treatment from traditional practitioners, others can only be effectively treated with allopathic medicine:

“Those 'curanderos' (native healers) do not know about that [referring to his hernia\}. Of course they may know about the swelling, but curanderos, shamans using ayahuasca (a ceremonial drink used for healing purposes), they don't know."

(Hospital patient Amazon)

A community healthcare leader in a small rural Amazon village echoes a similar sentiment about the incompatibility of traditional medicine and surgical disease:

"Hernia is something very, very special. When a surgery is done, it is very specific. Why? Because it is not like a cold, where you take pills so that the problem ends. It is a tumor. That hernia must be removed. We are obligated to do a surgery and we have to use medications in order to treat the pain."

(Community Leader Amazon) 
One elderly patient from the Amazon, who was diagnosed with cataracts, explained that he sought care from physicians as first line. He actively avoided treatment from traditional healers because he explained that cataracts are a condition that can only be cured surgically. He eventually gave up pursuing surgery because of multiple delays in the hospital system, but continued to insist that traditional treatments would be ineffectual for a surgical disease.

\subsection{Facilitators:}

\section{1) The Benefit of the Family Unit}

When the rural patient faces a surgical disease, the burden of having to separate from the family or the burden of having to assume a cost to maintain the family unit, are eliminated when surgical care is brought to the patient's community. With surgical care provided in the community, patients well-beingincluding his financial stability_-benefit from having the family close to them. For examples the financial hardship of transporting the family to the hospital is avoided:

"And of course, to be cared for in [the patient's] setting, signifies no expense for the transport, not having to spend to transport the family."

(Cinterandes anesthesiologist)

The family also plays a vital role in a patient's recovery post-surgery. Patients clearly reported that the availability of a family member to become involved in the post-operative care influenced their decision to go through with surgery or not, especially if the patient was an elder or lived alone. In the following example, an elderly man explains that he will only pursue surgery for his hernia if he is able to convalesce with the support of his children:

"After my wife died, I was alone, so I told my children: who is going to care for me when I get operated? I don't have anyone. My children would say: Father, get the surgery. I said, no. And when I got the second one [meaning the second hernia], I told my daughter, I have two hernias. She told me, father get operated. I said: who will take care of me? I am alone, your mother does not live. Afterwards, my daughter told me: Father I will take care of you, all our brothers will try to help you. So then, I was motivated to get the surgery."

(Cinterandes patient) 
Cinterandes healthcare providers reported that families of rural patients often actively participated in the recovery of the surgical patient. They noted that the family's role in post-operative care seems to provide psychological benefit to the patients, and leads to an overall positive clinical outcome.

"In our [Cinterandes] way of working it is different. We involve the family because we think that in the recuperation of the patient, the participation of the family is very important. We believe that a patient feels much better when he is surrounded by family and if partially being cared for by the family. We believe that psychologically the patient feels calm and much better, therefore we have included this as part of our care, the participation of family for the post-operative care."

(Cinterandes healthcare provider)

When asking hospital surgeons about patient's post-operative recovery within hospitals, they stated that surgery causes a significant physical and psychological stress on any patient. Being restricted from seeing family members - as it is common practice to allow family visitation at hospitals during very strict time frames - influenced patient's affect and clinical recovery. A surgeon who worked at a large city hospital and at Cinterandes, when comparing both settings in terms of outcomes, he stated that the post-surgical recovery time for the hospital patient is longer than the Cinterandes patient because Cinterandes patients have constant access to being with their family members which is a benefit for patients' psychological well-being as well as clinical state:

"For the Cinterandes patient, because the operation is done in their own community, I think that recovery is faster for them because they are with their family. The patient that goes to large hospitals, they become easily depressed because they are not with their families or loved ones. They enter a phase of severe depression and added to the surgical stress, sometimes lead them to spend many more days at the hospital. In the mobile surgical unit, the following day after an operation, the patient already has a smile on their face, and everything is good. Truly he is different; he is different from the patient that receives care at public institutions."

(Cinterandes \& hospital surgeon)

\section{2) “Socialización"}

Various informants recognized the need to address fears which inhibit rural patients' decisions to seek surgical care. Patients, community leaders and the Cinterandes team recognized the importance of familiarizing, informing and educating patients about surgery through a process identified as

socialización. This process consists of personal interactions between professional healthcare or surgical 
care provider and patients or potential patients to educate them about (1) surgery in general (2) their specific surgical illness and (3) what they can expect from the surgical process. In addition, the provider will address patient's fears surrounding surgery. After a patient undergoes this process and he becomes equipped with information about surgery, surgical illness, what to expect and after their concerns and fears are addressed then the patient is considered socializado.

Cinterandes workers have embraced this process of socialización, and they explained that when a patient goes through this process, they are more likely to remain and complete the surgical care process. The process removes stigma about the surgical care process so that fears of patients surrounding surgery can be mitigated. A nurse from the Cinterandes Foundation explains:

"As I was saying, because people do not know, they are afraid; they do not know what could happen to them. As you know, they come from rural areas to go to public hospitals, and they are not treated well, so they experience fear, so what happens is that people get tired and they leave [surgical care]. But for example through integrative health projects, people can be made aware, people can be taught, make them socializados. All those who are socializados, they will understand. If not socializado, people will be afraid. And people will leave [surgical care] and for that reason people in rural areas continue to suffer."

(Cinterandes healthcare provider)

Community leaders praised this educational process as a key component in reducing peoples' fears of surgery. They explain that it has been effective in addressing and mitigating patients' surgery-related stress and doubts

"Many times people who are not socializado say that the operation will be a failure and that one can die. That is the fear people have, they are afraid, but now with the Cinterandes Foundation it is no longer like that."

(Community leader)

"The person has stress, there is shyness. Some say will I be cured or not? Will I die or not? Those are the doubts people have. Those doubts give uncertainty. In order to make people feel safe and remove their stresses, we must use psychology through socializacion.

(Community leader) 
Various informants mentioned that different stakeholders should be involved in efforts of socialización. It should be a collaborative process between healthcare providers, community leaders, community members and even government officials. It was mentioned that the government should aim to institute socialización as a way to reach rural patients more effectively. Nevertheless, patient informants stressed how important it is for physicians to take initiative in the efforts of socialización in order to bridge the knowledge and communication gaps with rural patients. A patient stated:

"It is the obligation of the doctor to do socializacón, so that they can communicate about health campaigns and explain about health issues." (Hospital patient Amazon)

Moreover, the patient mentioned that in order to have effective communication with rural patients about surgery, socialización must be the first step in the process between the doctor and patient interaction and that the physician must be a charismatic and kind individual:

"If you are going to do a surgery, the first step is to do socializacón with the patients, it is best to do socializacón...And this should be by a person who is very charismatic. He must be humanistic in nature."

(Hospital patient Amazon)

\section{3) Home Visits by Surgeons or Physicians}

Physicians, patients and community members reported that patient home visits from a physician or surgeon had a powerful impact at various levels of care. Cinterandes' caregivers noted that the act of having a physician visit a patient's home was a key component of reducing surgical delay in some of the populations they served. An anesthesiologist with more than twenty years of experience working with rural communities explained that rural populations may not seek care because often they do not have information about their surgical diseases. In-home visits address this delay because they provide opportunities to educate patients about surgical disease - a service that this physician believes is a defining feature of the delivery of surgical care to rural populations.

"Now doctors have better understanding about what needs to be done in rural areas, it is another type of medicine. We say in rural areas, the patient does not go to the doctor; it is the doctors that should go to the patient. It is the correct form of action in the rural area. It is due to lack of knowledge that a patient does not go [to the healthcare facility], therefore the doctor needs to enter a patient's home."

(Cinterandes anesthesiologist) 
Healthcare providers also recognized that early stages of surgical conditions may be asymptomatic or have mild presentations. In the absence of detectable symptoms patients may not be driven to seek care at a healthcare facility located far from their rural setting. This often results in surgical disease going undiagnosed and untreated for extended periods of time. When physicians visit the homes of rural patients, they are able to recognize the silent symptoms of surgical disease and prevent delays in diagnosis and care:

"Doctors will find surgical pathologies which patients are not being treated for, from lack of going to the health centers. It is pathology that does not cause pain and therefore the patient waits a long time and does not worry much about it... [Going to a patient's home] has greatly influenced how to better serve in rural areas, as we used to say, to be able to find the pathology which was not being detected in rural areas."

(Cinterandes anesthesiologist)

In other cases some rural patients are aware of their surgical condition, but are reluctant to seek care because they are fearful of surgical services. Physicians' home visits play a key role in helping these patients to overcome these fears. One 73-year-old patient from a rural Amazon community describes how despite receiving a diagnosis of chronic inguinal hernia, he was fearful of receiving the surgery and preferred to put up with the pain:

"Yes, I went to the doctor and I was told, we will operate. I was afraid. I did not go in [to be operated], I mean that I went back home and did not do anything about it. And I remained that way, I worked, peacefully I worked, and after so long [50 years] I think the hernia became worse, that's when I felt pain."

(Cinterandes patient Amazon)

Cinterandes had visited this patient's community on several occasions, and had repeatedly advised him that he would need surgical hernia repair. While the patient's wife had successfully received surgery from Cinterandes, he nonetheless declined to pursue surgery for himself. The founder of Cinterandes, a general surgeon, learned about this individual and elected to visit the man in his home. Having a physician speak with him - in the very personal space of his home - helped him overcome his fear and pursue what had become a much-needed surgery, which he had neglected for 50 years: 
"The doctor came, they arrived right here [signaling to his home where the interview was taking place], and they examined me. We can operate, they told me, tomorrow first thing. Okay, I said okay."

(Cinterandes patient Amazon)

Patients and community leaders from remote settings in the Andes, Amazon and rural Coastal areas stressed the importance of having trained physicians visit their communities. Community members were careful to distinguish physician and surgeons from the "workers" that often visited their communities individuals with little formal training who carried out basic public health interventions.

"I have not seen any [physicians visit our community], but only workers that vaccinate, who are only licensed to vaccinate in the school. I have not seen any physician here from the health center so it seems almost impossible for a doctor from the hospital to come to the community."

(Healthcare community leader in Amazon)

A patient from a remote Andean community who received surgical care from the Cinterandes Foundation explained that receiving a home visit from a fully-trained physician helped minimize the social distance that she felt between her daily life and the medical realm. The physician's willingness to travel and enter her home was seen as an opportunity to engage in meaningful dialogue that helped her feel more connected to the surgical process, and helped the physician learn more about her needs:

"I will say, surgeons should be of greater support...like it has been done [by the Cinterandes doctor] that has accompanied us to our houses and has learned all about out us, that's what I would like...I think having the strength [the doctor] had in order to come, to accompany me, but they [other surgeons or physicians] will not do that... But without conversation there is no dialogue and they will not know how one feels...there are people that need this."

(Cinterandes patient)

\subsection{How Cinterandes Mobile Surgery Overcomes Surgical Access Barriers and Delays:}

Using the three delay framework, we will identify how the Cinterandes Mobile Surgical Program addresses surgical access barriers and delays. This framework for surgical access was described by the Lancet Commission on Global Surgery based on the three delay framework for maternal mortality (Barnes-Josiaha, 1998). 
The first delay is the delay in seeking care. Barriers that contribute to this delay affect a patient's decision to seek care, in other words, these are factors that would cause a patient to postpone care. These can include, geographic barriers, being disconnected from formal healthcare centers which should link the patient to a surgical facility, low awareness of available services, low trust in healthcare services, or financial barriers (Meara et al., 2015).

The Cinterandes model of care most evidently breaks geographic access barrier. The Cinterandes team along with the mobile surgical unit has traveled to communities in the majority of provinces throughout Ecuador providing care at urban, rural and remote settings (Rodas et al., 2005). One of the main goals of this program is "to deliver surgical care in the most remote places" of the country (Cinterandes, 2017). The provision of surgical care inside rural patients' communities is a revolutionary concept and impactful. Cinterandes mobile surgical care model completely removes the geographic barrier. The driver of many years of the mobile surgical unit stated:

"Interviewer: Where have you gone with the mobile surgical unit? Informant: We have gone to the Coast, the Andes and the Amazon Interviewer: What is special about your surgical services?

Informant: To be able to serve them in their [patients'] own home town, to serve them at their home, in communities where people never imagined anyone would arrive to provide them surgical care. We operate them in their own town, and sometimes we even take patients to their home and leave them resting on the patient's own bed. It is very rewarding."

(Cinterandes driver)

Patient's disconnectedness from a formal healthcare center which should otherwise connect the patient into the surgical care network, may affect patient's decision to seek care (Meara et al., 2015). Informants stated that rural health is unique in that it is the physician's obligation to reach the patient by going to the patient's setting. Because rural patients may lack knowledge about surgical care, they may not seek care. The Cinterandes mobile surgery program goes to the patient's community, in the rural or remote setting to 
reach the patient and provide care thereby connecting the rural patient to the health system. A Cinterandes anesthesiologist stated:

"Now doctors have better understanding about what needs to be done in rural areas, it is another type of medicine. We say in rural areas, the patient does not go to the doctor; it is the doctors that should go to the patient. It is the correct form of action in the rural area. It is due to lack of knowledge that a patient does not go [to the healthcare facility], therefore the doctor needs to enter a patient's home."

(Cinterandes Anesthesiologist)

Trust is built among rural patients through the Cinterandes model of care, by obtaining good clinical outcomes and through socialización efforts over time. Cinterandes has observed that often when they visit a new community, its members are commonly distrustful. Informants narrated that rural communities' historical distrust of the healthcare system and the state shapes the perception that outsiders may come with a secondary intention, such as political or religious ones. Cinterandes workers stated that in their model of care, the program builds trust among community members because of the development of a good reputation that is based on good patient outcomes and positive interactions with patients and education about surgery - a process which in our study, we have identified as socialización. The provision of surgical care inside the community along with good outcomes and socialización become powerful tools to gain patients' trust that influences their decision to seek care:

"It is complex and it requires many years of work educating people. We have invested a lot in this here at the Foundation. At the beginning people were very distrustful, every time we visited a new community, they always viewed us with distrust, such as, what do we want in exchange. Historically, people have gone to ask for votes or for a religious matter. We do not do that. At the beginning the people do not trust us, but later, when we demonstrate with our results and overtime, next occasions we visit them, they are more open [to surgery \& Cinterandes]. Surgery becomes the door into the communities because of our dramatic surgical results."

(Cinterandes Surgeon)

Lastly, another way Cinterandes overcomes the first delay is by addressing patient's financial barriers which has been identified as a main barrier among rural and indigenous communities that hinder access to healthcare (Larrea et al., 2006). It is a burden for patients to assume costs directly or indirectly related to 
surgical care. Cinterandes provides free surgical care to people who live in rural and remote settings with who live in poverty. In the words of the founder Dr.Edgar Rodas:

"When we go to towns that are far away and very poor, we don't charge absolutely anything. The idea is that no body, no body! Cannot! Not have an operation, because they do not have enough money" (Seely, 2010).

(Cinterandes Founder)

The second delay is the delay in reaching a surgical care facility (Meara et al., 2015). The ability to reach a hospital that provides surgical care is affected by various factors. It is affected by the geographic distance from rural settings and cost of travel, both of which have been previously shown that Cinterandes can address. In addition, the ability to reach care is influenced by the duration of the referral process from the primary care center to the hospital. In the Ecuadorian system, rural patients who seek elective surgical care must first be referred by the primary care physician to the first level hospital. Various informants revealed how delays in the referral process keep patients from being able to reach a surgical facility; it may take months or even years. A Cinterandes surgeon explains how the Cinterandes mobile surgery program can bypasses factors that contribute to this delay in reaching care because mobile surgical care is taken directly to the community.

"Many of our patients who come for an elective surgery... with a diagnosis of hernia or cholelithiasis tell us that they went for care to the health center and were examined, but their problems were not resolved, and they have been with the problem for two years. The patients are not given a solution, they are told to return in four months, and they couldn't because they have to work or they have other reasons like the high costs of transporting themselves. So for them the mobile surgery model is very convenient, because we are inside the community."

(Cinterandes surgeon)

The third delay is the delay in receiving care (Meara et al., 2015). This is the time that it would take for a patient who has arrived to a hospital to receive his surgery. Informants narrated that the arrival to a hospital does not guarantee that a patient will receive surgical care because the hospital's surgical services are not functional. This is consistent with the previous finding that primary level hospitals—which are commonly most proximal to rural settings - often do not offer surgical services outside their daytime business hours because of strict physician schedule policies. A surgical provider stated 
"One the patient arrives to a hospital, there is no guarantee that the hospital will provide surgical services. For example a patient from Shaime (a remote town in the Amazon) arrives to the nearest hospital, but they couldn't do the laparotomy because it was $8 \mathrm{pm}$. The patient has to go to another hospital, and that implies delays which have impact on morbidity and mortality of the patient. With us at the mobile surgical unit, we have the pontentail to break those delays."

(Cinterandes surgeon)

Moreover, the Cinterandes mobile surgery program also has the capacity to provide more specialized levels of surgery such as surgical emergencies or trauma surgical care. Cinterandes physicians shared about the variety of surgical cases which they have successfully managed in the mobile surgical unit. Even though it is not Cinterandes' objective to provide emergency care, in emergency situations, such as the Ecuador earthquake, they successfully managed critical patients. This means that the delay in the referral of a patient from a primary level hospital to a higher level care hospital—with more specialized care- is also avoided.

"Even though we are doing elective surgery, we have the possibility of doing emergency surgery. It is not our goal, but we have done emergency surgery. We have done C-sections, we have had polytraumatized patients. We have had one post-traumatic nephrectomy. We've had patients from motor vehicle accidents, acute abdomens, appendicitis, cholecystitis. During the earthquake we had a patient with a hemothorax, we solved it in the surgical unit."

(Cinterandes surgeon)

\subsection{Understanding the Cinterandes Mobile Surgery Model of Care}

\section{Types of Surgical Missions:}

Cinterandes provides surgical care using two types of surgical missions (1) short term missions which are one to two days in duration, and (2) long term missions which are 4 days in duration. These are determined by community proximity to Cinterandes headquarters.

Short-term missions are commonly in the outskirts of Cuenca city, while long term missions can be in any province of Ecuador. Cinterandes has travelled to the three distinct geographic regions of the Ecuadorian landscape, coast, Andean highlands and Amazon rainforest. 
In one day short-term missions, patient is released on the same day of surgery. Two day shortterm mission, surgeries are done on day one and patients released on day two with overnight nursing care. The Cinterandes team is present during both days of the mission.

Short-term missions' post-operative follow-up is done in person by the Cinterandes team by returning to the patient's community

For all missions preparation prior to surgical mission is the same

\section{Preparation before Surgical Mission:}

$>$ Mobile surgical unit along with surgical equipment is provided maintenance and evaluated for optimal function. If any issues are found, they are addressed immediately. Before the mobile surgical unit is deployed to the next mission, all components must function optimally.

$>$ Surgical supplies are replenished following high standards or surgical sterilization processes.

$>$ The community's healthcare provider or leader will contact the Cinterandes team and request mobile surgery services

$>$ Various communication exchanges will take place between local surgical stakeholder and Cinterandes coordinator to coordinate mission

$>$ Local community leadership approve expected Cinterandes mission. If local leadership does not approve, surgical missions will not occur.

Local surgical provider or leader will identify patients and enlist them in a potential patient list. They will need patient's information including, name, potential diagnosis, age, gender, height, weight, comorbidities.

$>$ Patients will be required to have laboratory or imaging tests done. These will be provided to Cinterandes physicians upon arrival to the community

For short-term mission, pre-operative surgical consult is done in-person with Cinterandes physician, one week prior to surgical care 
For long-term surgical mission, pre-operative first assessment is done remotely via the help of the local healthcare provider or community healthcare worker; and pre-operative healthcare consult will be done on day one of the surgical mission

Table 2. Model for Long-Term Cinterandes Mobile Surgical Mission and Barriers Addressed

\begin{tabular}{|l|l|l|}
\hline $\begin{array}{l}\text { Day 0: Mobile surgical unit travels to } \\
\text { community }\end{array}$ & $\begin{array}{l}\text { Barrier or Delay } \\
\text { Addressed }\end{array}$ & $\begin{array}{l}\text { Explanation how barrier is } \\
\text { addressed }\end{array}$ \\
\hline $\begin{array}{l}\text { Mobile surgical unit travels one day prior } \\
\text { to Cinterandes team arrival to the } \\
\text { community. }\end{array}$ & & $\begin{array}{l}\text { Bring surgical facility to the rural } \\
\text { community }\end{array}$ \\
\hline $\begin{array}{l}\text { Surgical unit is strategically parked by a } \\
\text { health center or community center }\end{array}$ & Geographic & \\
\hline $\begin{array}{l}\text { Mobile surgical unit is prepared, equipment } \\
\text { assembled. Sterilization surgical standards } \\
\text { are followed }\end{array}$ & & \\
\hline $\begin{array}{l}\text { Post-operative location is identified by } \\
\text { Cinterandes nurse and will be prepared on } \\
\text { day one. }\end{array}$ & & \\
\hline
\end{tabular}

\begin{tabular}{|l|l|l|}
\hline $\begin{array}{l}\text { Day } 1 \text { surgical mission: } \\
\text { Cinterandes team travels to communities } \\
\text { \& Pre-operative patient consults }\end{array}$ & $\begin{array}{l}\text { Barrier or Delay } \\
\text { Addressed }\end{array}$ & Explanation \\
\hline $\begin{array}{l}\text { Cinterandes team travels and arrives to } \\
\text { communities }\end{array}$ & Financial, Biosocial & $\begin{array}{l}\text { Patient's expenses avoided, } \\
\text { including direct and indirect } \\
\text { surgical costs. Ex: patient travel } \\
\text { to healthcare/surgical care } \\
\text { facility; family travel to hospital } \\
\text { in urban setting, lodging and } \\
\text { food; minimize missed time from } \\
\text { work }\end{array}$ \\
\cline { 2 - 3 } & Geographic & $\begin{array}{l}\text { Surgical Care is provided via a } \\
\text { mobile surgical unit inside } \\
\text { patient's community }\end{array}$ \\
\cline { 2 - 3 } & Weak surgical teams & $\begin{array}{l}\text { Cinterandes strong interpersonal } \\
\text { relationships are built throughout } \\
\text { the missions. Strong professional } \\
\text { relationships accountability, } \\
\text { dependability, team camaraderie. }\end{array}$ \\
\hline
\end{tabular}




\begin{tabular}{|c|c|c|}
\hline $\begin{array}{l}\text { Cinterandes team interacts with local } \\
\text { healthcare providers, community leaders to } \\
\text { ensure mission will be carried out as } \\
\text { planned }\end{array}$ & Distrust, Biosocial & $\begin{array}{l}\text { Build community trust through } \\
\text { personal communication } \\
\text { between Cintearndes healthcare } \\
\text { providers and workers with local } \\
\text { leaders }\end{array}$ \\
\hline $\begin{array}{l}\text { Post-operative patient recovery location is } \\
\text { identified and prepared with Cinterandes } \\
\text { team and local surgical care organizers }\end{array}$ & Distrust & $\begin{array}{l}\text { High safety standards are } \\
\text { ensured by surgical providers' } \\
\text { identification and approval of } \\
\text { post-operative recovery section }\end{array}$ \\
\hline $\begin{array}{l}\text { Patient Consults: All potential patients are } \\
\text { examined to come up with a final surgical } \\
\text { patient list. All patients have provided } \\
\text { evidence of appropriate pre-operative } \\
\text { laboratory results. Patients who do not } \\
\text { meet surgical requirements for safe surgery } \\
\text { are excluded and instead referred to } \\
\text { hospital care. }\end{array}$ & Distrust, Biosocial & $\begin{array}{l}\text { High safety standards are } \\
\text { followed } \\
\text { Socialización to educate patients } \\
\text { about surgical illness, surgical } \\
\text { process and address any } \\
\text { questions or concerns }\end{array}$ \\
\hline $\begin{array}{l}\text { Final surgical patient list is determined, } \\
\text { surgical patients will be scheduled to } \\
\text { receive surgery in days } 2 \text { and } 3 \text { or the } \\
\text { mission. }\end{array}$ & Distrust & $\begin{array}{l}\text { High safety standards are } \\
\text { followed } \\
\text { Low risk patients approved for } \\
\text { surgical care }\end{array}$ \\
\hline $\begin{array}{l}\text { Patients are instructed on pre-operative } \\
\text { preparation and instructions for surgical } \\
\text { day }\end{array}$ & $\begin{array}{l}\text { Distrust, Unfamiliarity } \\
\text { with surgeons, doctors } \\
\text { and surgical } \\
\text { procedures }\end{array}$ & $\begin{array}{l}\text { Clear instructions provided by } \\
\text { surgical care provider, in a } \\
\text { respectful and safe environment. }\end{array}$ \\
\hline $\begin{array}{l}\text { Throughout the day the Cinterandes is } \\
\text { interacting with patients and the } \\
\text { community }\end{array}$ & $\begin{array}{l}\text { Distrust, Unfamiliarity } \\
\text { with surgeons, doctors } \\
\text { and surgical } \\
\text { procedures, Biosocial }\end{array}$ & $\begin{array}{l}\text { By using SocializaciónTo talk } \\
\text { about their surgical illness, to } \\
\text { informe them of surgical care, to } \\
\text { instruct them on surgical } \\
\text { procedure, what to expect. } \\
\text { Cinterandes answers any } \\
\text { concern. }\end{array}$ \\
\hline
\end{tabular}

\begin{tabular}{|l|l|l|}
\hline $\begin{array}{l}\text { Day } 2 \text { and Day } 3 \text { Surgical Mission: } \\
\text { Surgery days }\end{array}$ & $\begin{array}{l}\text { Barrier or Delay } \\
\text { Addressed }\end{array}$ & Explanation \\
\hline $\begin{array}{l}\text { Patients are commonly accompanied by } \\
\text { multiple family members }\end{array}$ & $\begin{array}{l}\text { Responsibility to } \\
\text { Family Unit }\end{array}$ & $\begin{array}{l}\text { Separation from the family unit } \\
\text { is minimized }\end{array}$ \\
\hline Pre-operative patient preparation & $\begin{array}{l}\text { Unfamiliarity with } \\
\text { surgeons and doctors }\end{array}$ & $\begin{array}{l}\text { Patient is interacting with the } \\
\text { Cinterandes healthcare providers } \\
\text { upon arrival to the mobile } \\
\text { surgical unit site. Any questions } \\
\text { and concerns are addressed }\end{array}$ \\
\hline
\end{tabular}




\begin{tabular}{|l|l|l|}
\hline $\begin{array}{l}\text { Surgical procedures in the mobile surgical } \\
\text { unit }\end{array}$ & Financial barrier & $\begin{array}{l}\text { Surgeries are free for people in } \\
\text { rural and remote settings. Direct } \\
\text { and indirect -costs of surgery } \\
\text { avoided }\end{array}$ \\
\hline $\begin{array}{l}\text { Immediate post-operative care: patient is } \\
\text { transferred to the post-operatie recovery } \\
\text { location. Post-operative care is done by } \\
\text { Cintearndes healthcare provider. Family is } \\
\text { present to accompany the patient. }\end{array}$ & & $\begin{array}{l}\text { Family's presence and } \\
\text { involvement in care is beneficial } \\
\text { to the patient's clinical outcomes } \\
\text { and affect. }\end{array}$ \\
\hline $\begin{array}{l}\text { Family member becomes involved in } \\
\text { patient's post-operative care by observing } \\
\text { patient's, and relaying any concerns about } \\
\text { patient to Cinterandes healthcare provider }\end{array}$ & Delayed recovery \\
\hline $\begin{array}{l}\text { Safe and appropriate management } \\
\text { throughout the post-operative phase by } \\
\begin{array}{l}\text { Cinterandes healthcare provider in } \\
\text { collaboration with member }\end{array}\end{array}$ & $\begin{array}{l}\text { Family's presence and } \\
\text { involvement in care is beneficial } \\
\text { to the patient's clinical outcomes } \\
\text { and affect. }\end{array}$ \\
\hline $\begin{array}{l}\text { All post-operative patients must meet } \\
\text { criteria to be released home. Depending on } \\
\text { the surgical procedure and stability of the } \\
\text { patient. The patient may be released the } \\
\text { day of surgery of the day after surgery. }\end{array}$ & & \\
\hline $\begin{array}{l}\text { For patients who stay overnight, nursing } \\
\text { care is provided overnight continuously. } \\
\text { and physicians are available on-call } \\
\text { overnight. }\end{array}$ & & \\
\hline $\begin{array}{l}\text { Cinterandes surgeons, anesthesiologists } \\
\text { and }\end{array}$ & & \\
\hline
\end{tabular}

\begin{tabular}{|l|l|l|}
\hline $\begin{array}{l}\text { Day } 4 \text { Surgical Mission: Post-operative } \\
\text { care }\end{array}$ & $\begin{array}{l}\text { Barrier or Delay } \\
\text { Addressed }\end{array}$ & Explanation \\
\hline $\begin{array}{l}\text { Morning patient rounds by the Cinterandes } \\
\text { team }\end{array}$ & & $\begin{array}{l}\text { Evaluation of patient by } \\
\text { Cinterandes surgical providers. }\end{array}$ \\
\hline $\begin{array}{l}\text { Physicians also interact with family } \\
\text { members and community members }\end{array}$ & Distrust, Biosocial & Socialización \\
\hline $\begin{array}{l}\text { Before patients can be released, they must } \\
\text { meet clinical criteria and be accompanied } \\
\text { by a family member at all times. }\end{array}$ & & \\
\hline
\end{tabular}




\begin{tabular}{|l|l|l|}
\hline $\begin{array}{l}\text { Upon meeting criteria, patients and family } \\
\text { members are instructed on post-operative } \\
\text { care at home. }\end{array}$ & $\begin{array}{l}\text { Delay in patient } \\
\text { recuperation }\end{array}$ & $\begin{array}{l}\text { Family is involved in the post- } \\
\text { operative care of patients. This } \\
\text { promotes good clinical } \\
\text { outcomes. }\end{array}$ \\
\hline $\begin{array}{l}\text { Healthcare or community leader is } \\
\text { provided with an ipad for post-op patient } \\
\text { follow up at 1 week. }\end{array}$ & Geographic & Via the use of telemedicine \\
\hline $\begin{array}{l}\text { All patients are scheduled for the one week } \\
\text { post-op visit at surgical location with the } \\
\text { community healthcare provider or } \\
\text { community leader in charge. }\end{array}$ & Distrust & Continuation of care is provided \\
\hline $\begin{array}{l}\text { All patients are given Cinterandes surgical } \\
\text { provider's cell phone number to inform } \\
\text { them about any patient concerns or } \\
\text { abnormality }\end{array}$ & Geographic, Distrust & $\begin{array}{l}\text { Patient has access to Cinterandes } \\
\text { healthcare provider 24 hours a } \\
\text { day, 7 days a week } \\
\text { Promotes patient confidence }\end{array}$ \\
\hline $\begin{array}{l}\text { All patients are released home under strict } \\
\text { clinical safety criteria }\end{array}$ & & \\
\hline
\end{tabular}

\section{Post-Operative Care via Telemedicine}

$>$ At all times, patient's safety and well-being is priority for the Cinterandes healthcare providers.

All patients return to the surgical mission location to meet with local healthcare provider or community leader for the 1 week post-op follow up via telemedicine.

$>$ Via the use of the Ipad or other mobile devise, Cinterandes physician speaks with patient to ask how they feel

$>$ The Cinterandes providers will examine the patient with the assistance of the local healthcare provider or leader

Pictures of the surgical wound is taken and sent to Cinterandes team for evaluation

If any complication is encountered, medications may be prescribed and further instructions provided. If clinical evaluation is required, local healthcare provider will continue to monitor care 
to the patient. If the situration requires it, the patient will be taken to hospital with the help of the local healthcare provider or community leader

The Cinterandes surgical providers are also available to return to the community if the situation requires it.

Patients have access to Cinterandes physicians by telephone 24 hours a day, 7 days a week.

$>$ If no complication is found, patient is instructed to inform the Cinterandes doctor any abnormalities or concerns. Patient is reiterated that the Cinterandes physician is available 24 hours a day, 7 days a week so that they can communicate about any concerns.

$>$ If any patient does not attend the 1 week post-op telemedicine consult, the Cinterandes physician will contact the patient by phone and do a phone follow-up instead. The patient has access to a smart phone, the patient will be asked to take a picture of the wound and send it to the Cinterandes physician. If the patient does not have a smart device, follow up is done by telephone, or the local community healthcare provider or leader will visit the patient to ensure he/she is doing well.

Patients are scheduled to return to the mission site with the local health provider or leader at 1 month post-op.

Consults are done at one month post-op the same as it was at 1 week.

6 months and 1 year follow up as done via the telephone between Cinterandes and the patient.

$>$ The local stakeholder sends the ipad to the Cinterandes headquarters after post-operative follow ups are complete. 


\section{DISCUSSION}

\subsection{Analysis for Barriers, Delays and Facilitators}

\section{1) Unfamiliarity with Hospitals, Doctors and the Urban Setting Create Dear and Dissuade Rural Patients from Going to Hospitals}

For rural patients, seeking surgical care at hospitals is a very challenging experience. Various factors contribute to patient's fears which delay their ability to seek care. Hostility of unknown hospital and urban environments, not knowing how to navigate a hospital, lack of familiarity with surgeons and surgical procedures, and the removal of clothes during the physical exam are sources of fear for the rural patient which may play a significant role in decision making to seek care or delay the process or accessing timely surgery.

Informants often mentioned that their fear of urban hospitals often dissuaded rural patients from seeking surgical care. The urban environments where hospitals are located are often associated with delinquency and crime, and are viewed as dangerous for any individual in Ecuador, but even more so for the rural patient who is not familiar navigating a city. According to the United States Department of State, Guayaquil city, the most populated city of Ecuador, in recent years it has had a rise in violent crimes and low rates of conviction of criminals (OSAC, 2017). For a rural patient with limited resources, the threat of being robbed or hurt in the city poses a threat to his stability and therefore it is a deterrence to seek care in the urban setting.

Furthermore, surgical services are more commonly found at secondary or tertiary level hospitals which are large and crowded. Navigating the hospital system can be confusing for patients who are not familiar with the strict protocols required in the surgical care seeking process. These protocols are made up of various administrative steps so patients must navigate through multiple areas within the crowed hospitals. 
For rural patients that come from Andean or Amazon communities — who mainly speak a native indigenous language like Kichwa, Shuar or Achuar, navigating a health system that communicates only in Spanish, is a greater challenge. According to surgeons interviewed, this language barrier was recognized, so the regional hospital Vicente Corral Moscoso implemented a program that would help guide rural patients within the hospital. According to informants, this was a very effective program which greatly benefited rural patients, but unfortunately this program lasted temporarily due to limited funds to support sustaining this service.

Often, rural patients are unfamiliar with surgeons, surgeries or associated procedures; therefore the expectation of any experience related to surgery is frightening. The appearance and comportment of doctors compounded patients' sense of unfamiliarity and distress. Since the end of the nineteenth century, it has long been documented that a physician's white coat can affect patients (Parati, 2014). Scientific studies in the 1980's proved that the white coat can influence the development hypertension through the phenomenon called 'the white coat syndrome' (Mancia, et al, 1987). A physician's white coat is a symbol of power over patients seeking care (Nash, 2014). Likewise, as stated by the informants of this, the unfamiliarity with surgeons and the symbolic power of a surgeon's surgical attire and the knowledge that she/he may represent, influence a patient's fear about surgeon's capacity to inflict harm.

Procedures that are considered part of standard care practices may be viewed as a threat by rural patients. Being physically examined by a surgical care provider which requires the removal of the patient's clothes, provokes great fear within the rural patient. According to informants, the discomfort of removing their clothes was associated to feelings of shame. Informants highlighted that women experienced social shame if they were examined by a male physician. Literature demonstrates that shame is associated to healthrelated behaviors. In the context of HIV care, shame affected retention in care and adherence to treatment, and authors suggested that shame is a modifiable factor that should be targeted to improve care (Kohler et 
al., 2014). In the context of surgical care, we should consider that female rural patient's shame may be a modifiable factor. In order to promote surgical care seeking behavior and retention in care, shame can be addressed through education. Furthermore, unfamiliarity with other standard procedures associated to surgery such as signing a surgical consent may dissuade patients from surgery. If the content of a document is not well explained, the medical language contained in such forms is foreign and threatening. Therefore, the mention of the risk of death during a surgical procedure, if not carefully explained, can be interpreted as a death sentence.

\section{2) The Dual Effect of the Family Unit: responsibility for the family can dissuade care-seeking, while family support may contribute to patient's decisions to seek care and promote good outcomes.}

There are opposing influences of the family unit on patients. The responsibility to care and provide for the family is a factor that can discourage patients from seeking care. One the other hand, family support also emerges as an important contributor to the decision to seek care and obtain good patient outcomes.

In summarizing the results of our findings, regarding the responsibility patients have to care for their family, this study found that the stability of the family seems more important than personal well-being. Rural patients were willing to put up with surgical conditions as long as possible to avoid destabilization of the family unit. Regarding the benefits of the family unit, our research uncovered that surgical patients also benefit at multiple levels by having their family members near to them. By providing surgical care in the patient's community, rural patients have a financial benefit as transportation costs for family members — who normally accompany rural patients to distant urban hospitals in their surgical care seeking trajectory — are averted. Patient's decision to seek surgical care is strongly determined by the availability of family members to care for them post-operatively. Patients greatly benefited from family members' participation in their post-operative care. Surgical providers clearly recognized strong psychological and physical benefits, evidenced by a faster recovery time seen among patients who receive 
post-operative care from family members in the mobile surgical program, in comparison to hospital patients whose access to their family is greatly restricted in the hospital setting.

Considering that many rural patients like those from the Andean and Amazon regions are subsistence farmers, and those from the Coastal rural community were subsistence fishermen, sacrificing one or more days of work to seek surgical care is not a feasible option. According to the National Council of Labor and Salary (Consejo Nacional del Trabajo y Salarios (CNTS)), the minimum wage in Ecuador in 2016 was $\$ 366$ dollars per month (Astudillo, 2016). Among patient informants in this study, they reported wages ranging from $\$ 10$ to $\$ 15$ dollars per day, but some did not have any daily income and solely relied on their agricultural practices to subsist. In a survey conducted in 1998, assessing poverty and extreme poverty among indigenous and non-indigenous rural populations in the coast, highlands and Amazon of Ecuador, it was found that the most vulnerable populations at risk of poverty and extreme poverty were indigenous rural populations (Larrea, 2006). It was also found that the most common reason "why medical care was not sought in the event of illness or injury" was "not having enough money" (Larrea, 2006). It is understandable that rural patients who live in poverty feel obligated to postpone seeking surgical care.

For a subsistence farmer and head of household, it is difficult and perhaps impossible to be absent from work duties because that would translate to not being able to provide for his/her family. There are indirect financial expenses when seeking surgical care, such as time spent away from work, cost of travel to hospital, as well family's expenses to accompany patient like their transportation, food and lodging while in the urban hospital setting. Literature reveal the negative impact informal healthcare-related costs have on access to health care leading to under-utilization of services by people living in poverty (Falkingham, 2004). Therefore, to expect that rural and indigenous people who live in poverty have the ability to travel to distant urban hospitals to seek surgical care, at the expense of abandoning his/her own family is unfair 
and cruel. Social inequalities and poverty are at the basis of structural violence (Farmer, 2004). Rural people's subjection to poverty and the lack of stronger financial or social structures to help rural people provide for the family while seeking surgical care contributes to this violence.

Avoiding care seeking during early surgical illness presentations does not free patients from the long-term complications. Not being able to provide for the family subjects patients to prolonged suffering, while developing a complicated surgical pathology increases their risk of death and complications in the future. The postponement of care seeking is also a threat to the family. Patients and their families may face greater financial expense from having to confront an acute emergency surgery in the future than if it were done electively during earlier disease stages.

Historically, surgical care has been perceived as too expensive and difficult to implement in public health developments (Meara el al. 2015). Recently, the World Health Organization and global surgery investigators have revealed that surgical care is cost-effective and a good investment (Chao et al., 2014 and Hutubessy et al. 2003). In the context of rural patients' frequent postponement of surgical care to maintain the integrity of their family, it would be beneficial to analyze the cost the healthcare system is assuming to treat complicated surgical conditions, in comparison to what it would cost if those same conditions were treated electively, as non-complicated cases. Ecuadorian universal healthcare system assumes ambulance costs to transfer patients from healthcare facility near rural setting to hospitals in urban settings in cases of emergency (MSP, 2014). This cost could potentially be avoided if surgical disease were managed earlier in its disease process.

The rural patient must be seen from his social context. His family unit is a source of health, financial stability and overall well-being. Informants revealed that having the support of family members in the 
post-operative care of the patient is very important and will affect their decision to seek care. The benefits of maintaining the family unit may be overlooked in the standard system of care.

The Cinterandes mobile surgery model that uses family participation in the post-operative care of the patient has positive outcomes. Informants narrated that hospital patients who undergo a surgery are in a stressful state not only because of the procedure itself, but because of the separation from the family. Hospital patients are often depressed. One hospital patient explained how worried he had been because he did not know how his family would survive in the city. After undergoing his surgical procedure, he was particularly worried for his pregnant wife who would sleep on the hospital lobby with no money, food or family support. The emotional and psychological cost of threatening the family unit might not be considered in surgical care. The benefits of maintaining a patient close to his family should be considered. According to informants, the cost of bringing surgical care to the community via mobile surgical care to treat uncomplicated surgical cases may potentially avoid health system and patient expenses. Furthermore accessing early surgical care near or within communities would avoid the suffering patients endure when they have to be transferred to distant surgical facilities with acute surgical presentations.

When the family unit is maintained by the provision of surgical care in the patient's own environment, the patient's affect is positive and his post-surgical recuperation faster. As the surgeon who works in both, Cinterandes and the hospital, noted that Cinterandes mobile surgery patients recuperate well on the same day or one day after surgery. In comparison he mentioned the hospital patient may stay three days. Extended days in the hospital represent greater health risk and financial costs to patients and the healthcare system. Extended hospital days may also have negative implications for the family unit. 


\section{3) Distrust in the Public Healthcare System}

There are long standing perceptions of distrust in the public healthcare system. Perceptions of abandonment and invasion by the state have been acquired by rural patient's experiences. Rural populations lack availability of surgical specialists near their local settings as distribution of physicians is skewed favoring urban environments (Holmer, 2015). Historically, rural indigenous population has been manipulated through the health system, especially in the area of reproductive health. Recent experiences of seeing or hearing about poor surgical outcomes and ineffective medications, all contribute the negative perceptions about quality of care and trust in the healthcare system.

Violent colonization of indigenous people in the past and present and history of indigenous resistance as a response to colonialization practices have characterized the rural social reality. It is well documented that indigenous populations of Latin American have suffered a long colonial history marked by European invasion, exile and subjugation to European power. Nevertheless, colonizers have also found a long legacy of strong resistance to social inequities by organized indigenous movements.

Pre-Columbian Ecuador suffered invasion by the Peruvian Incan Empire, which was resisted by the Cañari people from Ecuador's Andean highlands who were not colonized by the Incas (Alchon, 1991). Later, despite entrance of Spanish colonizers, the Shuar people to this day continue to be known as the “unconquered people of the Amazon" (Perkins, 2001) when in 1599 the Shuar drove away the Spanish conquistadores (Kelly, 2012).

But colonialism did not end with the Spanish. During the "Wars of Independence" (CONFENIAE, 1984) Ecuador gained its independence from Spanish rule at the Battle of Pichincha in 1822. But it was actually national mestizo elites that came to dominate colonization efforts. For example, mestizo colonizers 
developed cattle ranches in the Amazon region in the mid 1930's claiming sovereignty over land, or the gold rush sent about fifteen thousand highland peasants to the Amazon region between 1940 and 1970 (Rudel, 1989). It was this national colonialism of the mestizo over the "indios" of the Amazon which contributed to defining class distinctions within Ecuadorian ethnic groups: the white-mestizo who was identified as the superior Ecuadorian culture and the untamed "indios" who needed to become free from the "aberrations" of the indigenous inferior culture (Dea Macanilla, 2009). In the mid-1900's the government institutionalized agencies like the Centers for Economic Reconversion (CREA), that were used to carry out colonization projects through the 1970's in the Morona-Santiago province bordering Peru. Through road development projects, CREA also strategically ensured sovereignty over land and resources in these regions (Rudel, 1989). The heritage of colonialism—supported by government and the institutionalization of social structures that overpowered and discriminated indigenous and rural populations - continue to resonate today in society and in the healthcare system. Rural population's long history of distrust in mestizos and government institutions would also transpire to shape distrust in the current public healthcare system and government, which are predominantly mestizo as well.

Indigenous population's distrust of the government is historically valid. As a response to indigenous communities' loss of territory to modern colonialism, rural people from the Andes and Amazon became motivated to form organized and institutionalized groups in an effort to gain political leverage and counteract colonial practices which contribute to their social inequality. In August, 1980 the Confederation of Indigenous Nations of the Ecuadorian Amazon (CONFENIAE) was formed; and in 1986 the Confederation of Indigenous Nationalities of Ecuador (CONAIE) was also established in order to gain political power over decisions affecting the people they represent. In the past, these indigenous organizations had collaborated with the government in anti-neoliberal efforts where the CONAIE was a key player. Neoliberalism began between 1982-1983, and it was the indigenous movement of the 1990's which would fracture the advancement of second generation structural reforms imposed by the World 
Bank and International Monetary Fund on the country’s judicial political and social institutions (Dávalos, 2014, p.99). But in recent years, indigenous institutions, rural communities and defenders of indigenous rights, have been in conflict with the government. Rural populations are being socially impacted by practices of extractivism - the exploitation of natural resources such as oil, mining and other resources. Unfortunately, extractivist practices often do not benefit local community development, but the capitalist market economies (Dávalos, 2014).

While in the field, we noted that the Shuar community where we conducted interviews was in precarious conditions, without electricity or running water despite the existence of the mining project for the past 5 years. Informants stated that the government has not provided much support for social and infrastructure developments. Moreover, Shuar community members feel that copper mining is negatively affecting their environment and health. Informants revealed that among the male community members who work in the mines, they have observed an increased number of hernias, which they directly associate to the physical exertion and long hours spent in the mines.

Another contributor to distrust is that those who received surgical care at the hospitals have developed very large and disfiguring scars which the community associated to low quality of care and distrust in the healthcare system. Therefore, poor surgical outcomes such as scar development or feeling pain during the surgical procedure, poor quality of care in the clinical setting as evidenced by unsatisfactory doctorpatient interactions, and a perceived lack of therapeutic effectiveness in the public health system all generate and augment distrust in the public system among rural communities.

Healthcare has often been used as a vehicle for controlling populations. The control of rural indigenous people through the use of family planning methods have been sources of human rights violations. 
Between 1996 and 2000, nearly 300,000 Andean women in Peru were sterilized without consent as part of the National Reproductive Health and Family Planning Program which sought to diminish poverty through low birth rates (Cavallo, 2016). In Ecuador, family planning programs are also a concern among rural people. Ecuadorian law which states that a citizen has the right to decide the number of offspring she chooses to have. An ethnographer observing healthcare facilities in the Morona-Santiago province revealed that healthcare providers were concerned over population growth as health officials had reported that Morona-Santiago province would undergo duplication in its population size in the following twenty years. They were concerned over fears of growing poverty in Morona-Santiago (Petersson, 2012). This supports our informant's concerns about birth control methods provided by public health clinics, which were viewed as harmful. Fears of government's attempts to "exterminate" indigenous people were vocalized.

Rural women's negative interactions with a healthcare structure such as the family planning program; and with social structures, such as oil and mining projects in Amazon communities, represent structural violence. The livelihood and health of rural communities are being affected. Communities are confronting greater disease or threat of disease. It was reported that significant weight fluctuations among women using publicly provided birth control and a greater number of hernias among males are being observed among community members. There were also fears of water contamination and a deteriorating environment. The biosocial context of rural populations should be considered when developing further efforts in healthcare and surgical care access.

Regarding other structures that threaten indigenous populations, in recent years, Ecuador has increased mining and oil concession in the Eastern and Southeastern Amazon. Morona-Santiago province is being affected. The government has claimed these projects will increase capital to eradicate poverty and support social development. But ironically, critics of the government mention that none of the money from such 
concessions is designed towards the maintenance of social development programs for indigenous communities (Davalos, 2014). Rural and indigenous people are being forced out other their ancestrally owned lands. Despite the existence of national laws and international treaties like UN's Declaration on Indigenous People (UNDRIP), recently on August, 2016, the government used military force to drive the indigenous Shuar community in Nankints out of their ancestral territories (Koenig, 2017). Humble homes were demolished, children, women and the elderly violently evicted to give way to mining by Chinese Explorcobres EXSA (Ling, 2017). Indigenous leaders have also been violently targeted. In 2014, Jose Isidro Tendetza Antun, a Shuar community leader who avidly opposed mining developments in Southern Ecuador was found dead with arms and legs tied but no evidence on who perpetuated his fatality was found (Democracy Now, 2014).

Structural violence is embedded in the establishment of oil and mining concessions by political powers. These extractive practices threaten the livelihood in rural settings. The laws that protect oil and mining companies provide companies' status as agents (Davalos, 2015) and these agents can compete with the rights of people. Oil and mining corporations with support of the government are imposing their agenda to gain capital and the expense of removing people from their ancestrally owned lands. This is a direct impact to rural communities' stability. It is also a direct threat to their health. Communities surrounding mining or oil extraction projects are forcefully exposed to the risk of environmental harms such as contamination of water sources and deforestation. In the following videos we can visualize the manifestations of the structural violence disrupting the livelihood of indigenous people. It is social injustice for rural communities to be displaced from their lands. Here is footage of a news report: https://www.youtube.com/watch? $\mathrm{v}=\mathrm{JiymyHh} 7 \mathrm{gMg}$, and the eviction from the perspective of a Shuar indigenous woman: https://www.youtube.com/watch?v=7Fv210q7-Fk. 


\section{4) Health System Inefficiencies}

Informants exposed various steps in the surgical care system that they considered inefficient, causing significant delays in the care seeking process. Some found it difficult to enter the referral process. While some attributed this to the inadequacy of the appointment system which did not seem to serve rural patients well, others attributed inefficiencies to the overall high demands of surgical care. In theory the referral process seems to be well planned and organized, but in practice healthcare providers perceived it as slow and sometimes ineffective. Some noted that there are disproportionate numbers of referrals between hospitals making some facilities oversaturated. Others mentioned that inaccurate diagnosis at the primary level of care caused significant delays. In the midst of the struggle to enter the referral process or difficulties in navigating through it, patients are found bouncing back and forth between the emergency departments and health clinics in hopes to find a definite solution to their surgical ailment.

It may be hard to pinpoint one main reason which would explain why a system that seems well defined on paper is perceived as a fragmented process from the view of the healthcare providers and rural patients. The discrepancy between how the referral process should work, and what patients actually experience is significant and warrants further attention.

In the public health system, there are two ways a patient can enter the surgical care process, either through the referral system for elective surgeries, or through the emergency department for acute surgical emergencies. In order to access care for elective cases, a patient must first obtain an appointment via the telephone or internet systems in order to be seen by a primary health care physician at a community health clinic. Many times rural patients encounter difficulties at this point because they can't access a telephone or computer. As the patient revealed, she had to borrow a neighbor's telephone. Telephone service is an expensive commodity in Latin America, which rural patients may not be able to afford. And internet services may not be accessible in rural or remote areas. According to informants, the health system does 
not offer an alternative method to schedule an appointment. Even when the patient physically reaches the health center, he is not offered assistance to access the telephone or internet systems as there are no telephones or computers on site. Instead they are instructed to access the telephone or internet services on their own. Imposing a requirement of a technologically advanced system when such technology is not standard to rural patients, inevitably result in a barrier to care. Ecuador is a developing country. Rural patients, and even more so, indigenous rural patients have the largest percentage of population among those who live under the poverty line (SIISE, 2017). Although it is more common for people to know how to use the telephone, rural and indigenous populations may not be familiar with navigating the World Wide Web.

Then, when a patient is able to get through the call or internet system, they find themselves with the reality that a doctor's appointment may not be available a month later. When a patient is experiencing symptoms from common surgical conditions such as acute having to wait for one month for care is unacceptable. Instead the patient might seek other options, such as going to the emergency room, going to other clinics or seeking alternative forms of healing.

From the perspectives of healthcare providers, the delays in the appointment system may stems from the overall high demand for surgical services. A long wait list of patients is formulated, and as the surgeon mentioned, although a patient truly does need surgery, they may have to wait 3 to 6 months before a surgeon can be seen. These circumstances that delay being able to obtain appointments with primary care physicians or surgeons are very dissatisfying for patients and surgical care providers.

There are other components of the referral process, that according to surgical providers and leaders require optimization. It was mentioned on various occasions that inaccurate surgical diagnosis at the primary level often causes delays. Specifically surgical specialists mentioned that patients may be referred to the hospital surgery department with paperwork not specifying a diagnosis. This was reported as a 
significant cause of delays because patients will face the need to take steps back in the referral process such as going to other departments to obtain necessary diagnostic exams. Patients that are referred to a hospital's surgical service are expected to arrive with a proper surgical diagnosis. Other specialists mentioned that primary care centers are often not equipped with necessary diagnostic tests that is sometimes needed for accurate diagnosis, but other times primary care providers may lack the skill necessary to specify a surgical diagnosis.

Moreover, surgical care delays are accentuated by the disproportionate number of referrals between hospitals. Hospitals are divided by into zones. In order to manage surgical cases, the surgical system is designed so that the primary level hospital will transfer patients to a secondary level hospital within its region. And if the secondary level hospital is unable to treat, patients are transferred to tertiary level hospitals. Sometimes this process causes delays, because theoretically lower level hospitals should be able to provide essential surgical procedures, but as mentioned previously, because services are not provided 24 hours a day, a referral is generated when a patient arrives to the primary level hospital outside the working hours. This causes oversaturation of patients at higher level hospitals. In addition, as a surgical provider explained that his hospital is designed to receive referrals from a few hospitals from within his specific zone, but in reality he received patients from hospitals outside of the hospital's regional zone.

The way this manifests in the patient experience according to our informants, is that if a patient arrives to the emergency department symptomatic but non-severe, they will be instructed to go back to the primary care center to obtain a referral pass from the primary care physician to the hospital's surgery department. It was widely reported that patients often found it very difficult to obtain that pass from the health clinic. According to patients, their ailments are often being dismissed as simple conditions such as "gases", "gastritis", or simply because the physician considers that the condition is not serious enough to be referred to the hospital. Another patient, very upset, stated that even though she repeatedly returned to the 
primary care physician to ask for a pass to the hospital to treat her umbilical hernia, she was told that she was too obese. She stated that her doctor required her to lose weight before he would transfer her to a hospital. Nevertheless, the Cinterandes who surgically treated this patient did not consider the patient obese. Patients consider that they often waste time bouncing between health facilities and hospitals without adequate treatment of their surgical conditions.

\section{5) Displacement of Decision Making Power}

Centralization has caused a power shift in decision-making on health system issues affecting surgical delivery. Strict schedule policies require surgical professionals to be hired by strict eight hours shifts. This has caused time gaps, predominantly in primary level hospitals, where surgical services are not available outside the eight hour timeframe. Under this stipulation, surgeons cannot be hired on an on-call basis. The combination of strict policies and unavailable surgical specialists near rural settings, have created a referral structure that forces surgical patients to travel for several hours in dire physical conditions. Also, because budget decisions are controlled centrally, at the state level, hospitals have limited or no ability to decide over budget adjustments to avoid interruptions of surgical services.

The post-neoliberal efforts by the government in the last ten years have had a direct effect on the healthcare system. The government became more centralized as part of the anti-neoliberal agenda. Decentralization was a feared strategy of the neoliberal agenda (Davalos, 2014). Healthcare became centralized, so that power shifted towards a few "zonal offices" and central office in the country's capital. The health system became standardized across different regions. So even if healthcare needs may vary among hospitals, everyone is expected to work within the confined standard structures. 
These standard structures may not have the malleability that is necessary to address varying or changing local needs. As a surgical provider mentioned, while it may be sufficient for a hospital to have an Ears Nose and Throat specialist for only eight hours in a day, it doesn't make sense to have emergency or surgical services for only eight hours. Trying to meet the gap of unavailable surgical services in one facility through ambulance transportation to another facility is only a temporary solution. Primary level hospitals which are expected to provide essential surgical services are under-utilized because of strict policies.

Inflexible surgical hours of operation and not having on-call surgical services, hinder the ability to move towards meeting sustainable development goals including the reduction of "premature mortality from non-communicable diseases through prevention and treatment", which include surgical conditions. Surgical structures need to be designed to meet the needs of patients. If a person is involved in a motor vehicle accident in a rural environment, it is irrational to accept that his transfer to a distant surgical facility three hours or more hours away, as the best solution. Although ambulance referrals between hospitals are helpful, they do not guarantee patient survival. Patients are not only subjected to prolonged suffering because of the long travel time, but their lives are at greater risk of death or complications. Primary level hospitals predominantly serve rural populations but do not commonly provide 24 hour care.

Therefore, hospitals should be granted increased decision-making power over health and surgical delivery structures, including surgical schedules, surgical on call services, budget decision in order to optimize local surgical care delivery. 


\section{6) Strong Regulations on Non-Governmental Organizations:}

Informants perceived that the government wants to possess the role as main operator of healthcare. Healthcare reforms included new laws to regulate all non-governmental organizations. Many NGO's were closed down upon implementation of the new laws. Limiting or annulling NGO participation in healthcare is perceived as persecutory action, giving rise to widespread political criticism. Populations served by the healthcare NGO's were reported to be abandoned, as services were not replaced by the state. The Cinterandes mobile surgery program has also felt limited in their ability to provide surgical care in certain rural regions. Nevertheless, Cinterandes is hopeful for the future; through dialogue and collaboration with government officials they are certain that access to surgical care in rural settings can be optimized.

Some of those informants affirmed that the constitution actually stipulates that healthcare is the responsibility of the state, only. Upon investigation, article 32 of the constitution establishes that "health is a right guaranteed by the state" and furthermore it highlights that "the state guarantees this right through economic, social, cultural, educational and environmental policies" (Asamblea, 2008). Being the agent that guarantees health rights is not the same as being the only or main agent for healthcare delivery. The view of the ministry's sovereignty in healthcare may be related to a misinterpretation of the constitution. Even though the ministry is the predominant agent in healthcare delivery, theoretically it should not have sovereignty over the private sector or vice-versa. Pragmatically, patients and providers perceive that the government wants to be the main or only player.

Under former President Correa's leadership, healthcare structures and implementation of centralizing policies seem to be aimed at monitoring and controlling institutions which are independent. During the Saturday television program which aired Correa every week, he responded to the interviewer who asked 
him to comment on the notion that "private healthcare facilities were refusing to accept [public] patients because of poor reimbursements by the state." Correa responded by saying: "Healthcare is a public service,

An executive order called Decreto 16 was implemented on June, 2013 which began a series of strong regulations imposed on non-governmental organizations (NGO's). Many NGO's have objected to the unconstitutionality of the decree, as it infringed on organizations' right of liberty of association, social participation, independence, the right to peaceful protest and political participation (Rojas, 2013; Puente, 2017). Under this new social structure, the government can dissolve any NGO — health related or not — if any of its members participate in any political organization or action, or if the government entity which "oversees" the organization determines that the NGO poses a threat to public peace or if the government officials consider that the organization has deviated from the purposes and mission. If a member of an NGO's participated in her civil right to protest peacefully, would be enough ground to annul the organization. This decree violates a citizen's right to protest. Subtly it categorizes an individual as a citizen or not a citizen by the removal of his rights. In the weekly Saturday program when President Correa was asked to comment on the problem between hospitals where public patients are being denied transfer to private healthcare facilities on the basis that there are reported problems on the reimbursement of payments by the state, Correa responded: "Health is a right, not a commodity. If necessary we will nationalize private clinics that do not cooperate with us" (Cuenca, 2015). This statement clearly shows that the government's authoritative use of power over the healthcare system is a tangible possibility.

Important healthcare programs have been closed because of this executive action. Informants highlighted the Los Andes Hospital, a well-equipped hospital serving rural and remote populations on the Amazon and Andes. Another well-known organization, Fundación Pachamama (mother earth) — that defended environmental rights and the health and livelihood of rural and indigenous people — was subjected to 
forceful closedown. After participating in a protest against oil extraction in Yasuní National Parkconsidered one of the most bio diverse ecosystems in the world (Bass et al., 2010) the Fundación Pachamama offices were forcefully closed without prior warning (Davalos, 2014).

For 27 years, the Cinterandes mobile surgery has successfully provided free surgical care in many rural

and remote communities throughout the country. They have undergone close regulation by the ministry of health since the implementation of the new decree and have met all government requirements to function legally. But in recent years, they have encountered situations which have caused surgical mission cancellations. In Feb, 2017, Cinterandes had to cancel a scheduled surgical mission to the town of Guadalupe, in the Zamora-Chinchipe, a very important mining province. Even though Cinterandes previously provided services in this region, they were informed by local stakeholders that the surgical mission would not be allowed to continue. Reasons behind the opposition to why free surgeries should not be provided to rural patients were not specified.

Nevertheless, every member of the Cinterandes Foundation considers that the future of mobile surgery in Ecuador and the world is very promising. After their long service trajectory they have gained great recognition in the worldwide stage, among surgical communities and academic medical societies. They have proven mobile surgery can be done with safety and high standards.

\section{7) Unique Remoteness of the Amazon}

The unique remoteness of the Amazon's geography and inaccessibility makes accessing surgical care extremely difficult for inhabitants of this region. Climate variations, extreme remote geographies, coupled with lack of motorized transportation and long distances, make the Amazon forest a uniquely remote environment that greatly challenge a person's ability to access timely surgery. Informants reported that 
the measures that rural patients are willing to take in order to obtain surgical care are extensive and even risky. The magnitude of risks seems to be equivalent to a patient's level of desperation for surgery.

We must consider that rural settings in Ecuador do not equate to rural settings in the United States or other developed countries. It is hard to imagine the level of remoteness and the challenges ill-patients endure if one is not born into similar social conditions. It is important to carefully examine and account forthe geographic realites of these rural and remote communities in order to thoughtfully and carefully designs healthcare or surgical care structures. People who live in the Amazon — and even more so those who live deeper in the forests — confront greater barriers to access.

The lack of social development projects in the rural Amazon poses a great barrier to surgical access. Improvements of infrastructure and transportation services are needed. Rural population's social inequalities are not only a consequence of their natural environment.

\section{8) Lack of Supplies Negatively Impacts the Delivery of Surgical care}

Surgical supply chain plays a vital role in timeliness of surgical care delivery and shape patients' perceptions about the healthcare system. Constant monitoring is required to ensure continuation of available supplies. Supply shortages occur at the national level's ordering system. At the regional level this may occur due to high supply demands. At the institutional level this may occur because facilities may not adhere to standard supply chain processes. Surgical supply stock-outs may delay surgical care delivery. This causes a shift in the responsibility of supply provision from the health system to the patient and his family. These effects contribute to negative perceptions about the healthcare system. 
Untimely availability of supplies may be related to the high number of health system reforms of recent years. Such structural changes have affected the management of administrative processes of supply chain. Adaptation to the new system is progressive, and optimization of processes gradual. The government has worked towards the improvement of the health system by investing in new hospital infrastructure; nevertheless it has also been criticized because the health system falls short in service delivery as evidenced by the intermittent lack of supplies and its interruptions in surgical services. "Fragmentation of the health sector persists, and both the ministry of health and the IESS services suffer patient dissatisfaction and quality problems.” (De Paepe et al., 2012). In an interview, former president Correa mentioned regarding IESS hospitals "the reality is tragic, and we must make changes quickly to assure the hospital is filling its mission of serving the people of Ecuador" (Cuenca, 2015). Furthermore, he blamed poor management as the culprit of financial problems in healthcare facilities (Cuenca, 2015).

It was confounding to hear about the conflict between lack of supplies and the responsibility to provide for them. Some healthcare providers stated that the government assumes full responsibility for the provision of healthcare services. Yet, when inquiring about what happens when a public healthcare facility is unable to make a provision, would the patient need to be responsible for acquiring the supply? The researcher was surprised to hear that the healthcare system does not encourage or even tolerate patients assuming out-of-pocket expenses for a supplies not provided by the health system. Medications must be made available free of charge by the public health facility. Multiple informants revealed that sometimes public system physicians, who prescribe medications to patients for purchase outside the hospital, are sanctioned! Nevertheless, patient informants of this study purchased medications that were not available at the hospital, commonly analgesics, or simple supplies such as syringes and needles. Most informants considered the cost of such supplies to be minimal, nevertheless there were a couple of patients informant or their families who were unable to assume the responsibility of out-of-pocket expenses. 


\section{9) The Conflict Between Assumptions and Practices About Rural Patient's Use of Traditional Medicine}

Concepts about rural patient's understanding of surgical illness and care seeking contradict between healthcare providers and the rural patients themselves. Among healthcare providers and affiliates, it was commonly perceived that rural patient's strong cultural connection to ancient healing practices and lack of knowledge about surgical illness were the main contributors to rural patients' delay in seeking surgical care. On the contrary, patients revealed that they clearly differentiated surgical from non-surgical illnesses. They understood that traditional medicine was limited to specific health conditions and that the option for traditional medicine is not always their first choice to care.

Without thorough analysis of rural patients' delays in care seeking, it is tempting and easier to place the responsibility on the patient, their beliefs and practices. Because rural populations are the ethnic minority of the country's population, they are often socially and culturally isolated. Rural Ecuadorians are commonly associated to their knowledge about medicinal plants and alternative forms of healing. Rather than analyzing the effectiveness of established healthcare structures or ease of access to surgical services, the healthcare workers may find it easier to blame rural patient's behavior as a main contributor to the delays in surgical access. The consideration that there may be shortcomings in the surgical delivery system is a first step towards objectively assessing it.

The lack of scientific evidence that patient's traditional medicine practices are the main reason behind delays in access makes this a facile claim shared among non-rural non-indigenous individuals. The perpetuation of these claims without basis, subjugate rural people to the generalization that those who hold such traditions are inferior in their ability to understanding disease. This is a colonial discourse in 
which ethnic distinctions are used to explain that rural populations do not understand health, because of their inferior knowledge. This process creates social inequalities - a culprit of colonialism —in surgical care access because rural patients will continue to be subjugated to healthcare systems which may not be designed or equipped to meet the needs of rural society.

On the contrary, informants revealed that patients do understand concepts about surgical illness. They know that while some illnesses may be treatable with traditional methods, surgical diseases were clearly identified by patients and even traditional leaders as conditions that require surgery. Informants understood that a surgical condition requires a surgical solution, and although they might be unfamiliar with surgical procedures, rural patients consider surgical care would be appropriate.

\section{0) "Socialización"}

Informants presented the concept of socialización as a process to familiarize, inform and educate patients about surgical disease, surgery and surgical procedures. One main goal of this process is to address fears patients have about surgery in order to promote surgical care seeking. It is particularly important for patients that socialización would take place as a first step in the interaction between physicians and rural patients to build trust.

The purpose of socialización is for rural patient to learn about surgical disease, surgical care and familiarize the community about surgery. Because rural populations have fears about surgery, surgeons, surgical care and associated procedures, it is considered important for socialización to be used as a way to bridge knowledge gaps that may exist among rural communities. Patient's fears contributed to losing patients to follow-up. In other qualitative studies about factors that contribute to losing patients to follow up, fear was a main contributor (Wolf et al., 2014). Therefore, this interactive process of socialización should aim to minimize fears of patients. 
Although it was stated that in socialización multiple individuals can contribute to this informative process, the physician was identified as the most important individual. Patients considered that part of a physician's obligation is to interact directly with rural patients and the community to provide accurate information through socialización. Rural patients expect the physician will use socialización to promote health in rural communities as well as decrease health risks that may stem from misinformation. The physician represented knowledge and power. The intrinsic power of physicians can be used to help and advocate for patients. A physician can make a significant difference in one patient's life or a whole community. Despite all limitations of the health system, there is always something that can be done, collaboratively with other colleagues, community members, healthcare leaders and organizations. Medicine has symbolic capital which is underutilized (Farmer, 1998).

Socialización is a tool which can be applied when serving rural patients. It can ameliorate fears about surgery, it can promote surgical care seeking, it can promote patient trust in surgical care system and it has the potential to break the biosocial barriers that exist between rural patients and the health care system. It is an opportunity for dialogue in order to amend a history of suffering and abuse endured by rural and indigenous patients.

\section{1) Home Visits by Surgeons or Physicians}

The act of a surgeon or physician visiting a patient in his home has transformative power. Home visits are a key component in rural health as information is brought to the patient. When a trained physician or rural surgeon visits a patient's home, surgical illness is being detected during its earlier stages. When a patient receives a healthcare provider in his home, barriers of reluctance towards surgery and related fears are eliminated. The effort of the doctor who goes to the patient is seen as an endeavor to break the social barriers that separate patients from the healthcare system. 
It was previously discussed that multiple factors contribute to rural patients' delay in deciding to seek care, care seeking behavior and accessing surgical treatment. Going to a patient's home has the capacity to break barriers at multiple levels.

Just as rural health is considered a subcategory within the medical practice, surgical providers highlight that rural surgical care is also different. The medical needs of rural patients may differ because of the previously established geographic, biosocial and health system barriers that exist. Rural patients are more likely to delay care seeking in healthcare facilities (Living Conditions Survey, 1998) and multiple informants highlighted that they are more likely to present to hospitals with complicated surgical conditions. Doctor's home visits have the capacity to detect surgical illness in its earlier stages.

The dialogue exchange that occurs between a doctors and patients in their homes share some similarities with socialización, but in socialización physically examining a patient and making a diagnosis is not part of the process. Nevertheless, going to a patient's home can be seen as an extension of socialización efforts. Through patient home visits, the dialogue about healthcare between doctor and patient is more targeted. Because rural patients may overlook milder surgical symptoms, doctors are able to inform them about the natural evolution of their disease if left untreated and about recommended surgical care and what to expect if patient decides to seek a surgical solution. In addition, doctor-patient dialogue can address specific fears patients have about surgery and help them overcome reluctance to surgery. In a study that examined why patients tend to decline a surgical procedure, researchers concluded that patients' fears contribute to reluctance to surgery and that these should be addressed (Hagensli et al., 2014). Physician and surgeon home visits provide an opportunity to enter the patient's intimate space to effectively address their fears and reluctance to surgery.

It seems that the personal interaction between physician and surgeon had a powerful effect. In one of the cases presented in the study, the patient had known about his surgical condition (a hernia) for about 50 
years. He had also been examined by the Cinterandes mobile surgical team during previous surgical missions in his community, but the patient remained reluctant to surgery although his wife had been successfully treated by Cinterandes as well. During the interview it was extremely hard to pinpoint the source of his reluctance. What marked the difference for this patient was to experience the presence of the surgeon himself in his own home.

The surgeon's action to go to the patient seemed to break the reluctance, fears and perhaps the patient's non-vocalized distrust. More than the exchange of words, it was the action of the physician which represented great concern. The home visit may signify to the patient, 'I care for you enough that I came to see you, I want your well-being, and I am here to help you.' Surgeon's ability to go out of his way, transformed the patient's thoughts and dismantled reluctance and fears.

The accompaniment of a doctor who visits a patient in his home is a powerful symbol because it represents that patient's lives are important and what they feel and perceive are valuable. Considering the history of colonialism and violence as well as their current manifestations, throughout the analysis of this study, we have seen that in general rural and indigenous communities feel abandoned, neglected and even persecuted by society, the government and the health system. The lack of support or attack on rural and indigenous people represents social inequality. Multiple rural patients reported they feel mistreated by the healthcare system. The degree of humaneness with which patients are treated contribute to the way an institution is perceived (Nead, 1999). The physician and surgeon have the power to change how rural patients view and experience the healthcare institution.

We can interpret from our analysis and narratives of patient informants, the accompaniment of a physician or surgeon symbolizes that rural patient's lives are valuable and what they feel and express are important. Surgeon or physician accompaniment can minimize the biosocial barriers of surgical care. This 
is an opportunity to amend the effects of social inequality experienced by rural communities and diminish perceived mistrust in the government and health system.

\subsection{Structural Violence Embedded in the History and Social Fabric of Rural Populations and Healthcare Structures}

In this study we have identified various social structures and forces that contribute to structural violence which hinder rural patients' ability to access timely surgical care. Throughout our analysis we have highlighted biosocial barriers that are shaped by historical, social, political and economic forces.

Colonialism played a vital role in shaping social inequalities among indigenous people. Native Ecuadorians were subjected to violence and control. What marked modern Ecuadorian social class distinctions based on ethnic differences was colonialism by National mestizos (Dea Macanilla, 2009). Indigenous people were viewed as an "inferior" race. Since then, social injustice based on ethnic differences has prevailed. Rural indigenous people are the most poverty-stricken group in Ecuador (Living Conditions Survey, 1998). Rural populations especially in the Amazon are being violently displaced by large international oil extraction and mining corporations. Rural communities are used as workforce to sustain these projects, without receiving direct benefit for social development. These modern colonial and political structures subject rural patients to poverty as well as to promote illness.

Inadequate surgical system structures contributed to structural violence and significantly delayed access to surgical care. We found evidence that there are very remote communities with little or no accessibility to healthcare services. Deficient social and healthcare structures force ill patients to walk for days to distant healthcare facilities. People in remote or rural settings are subjected to social isolation from the 
healthcare system. Therefore rural patients do not have the same access non-rural patients have. In addition, the healthcare clinics that are closer to rural settings are often not equipped with diagnostic tools or healthcare providers may lack surgical diagnostic capacity. The persistence of a system in which patients are unable to enter the surgical care process for months or years and finding themselves bouncing back and forth from a health clinics to emergency rooms without a surgical solutions, is a red flag for structural violence. The inappropriate telephone or internet appointment platforms for rural patients also contribute to structural violence. In addition the absence of 24 hours surgical and anesthesia care at primary level hospitals also contributes to surgical access inequities and structural violence. There are multiple health system structures that work inefficiently and therefore as barriers to surgical care.

Other political structures are also imposing structural violence. The strong regulations and even "percussion" of non-governmental organizations have led to patients losing access to healthcare provided by NGOs. Informants stated healthcare services have not been replaced by other institutions. The government is perceived as an institution that is insular. Collaboration with private healthcare institutions may be key to the optimization of surgical care access.

Gender roles in rural communities also created a burden to access, particularly for women. Rural patients feared the removal of clothes during a consult with a surgeon or physician. For women it was particularly difficult because husbands expressed opposition to women removing their clothes in front of male physician. Both male and females voiced this shared belief. Women are therefore particularly vulnerable because they are less likely to seek surgical care because of the shame and fear attached to the removal of clothes. 
Poverty is a huge form of structural violence impeding and delaying rural patient's ability to access surgical care. We previously stated, over $50 \%$ of Ecuador's rural population live in poverty. With the responsibility to provide for the family unit, patients must weigh between their ability to tolerate their surgical illness to postpone care over the risks of abandoning family or work to seek care surgical care in urban hospitals. Indigenous rural populations are the most vulnerable in society (Living Conditions Survey, 1998). Ecuador must seriously consider investing in surgical case access since it is estimated to promote a country's financial growth (Meara et al., 2015).

Multiple biosocial barriers presented in this study have been emerged from structures of social disparities of rural populations. These have contributed to the formation and perpetuation of structural forces which limit rural patient's ability to access surgical care.

\subsection{Redefining Cinterandes Mobile Surgery as a Community-Based Surgical Care Accompaniment Model}

Cinterandes mobile surgery has components of community-based accompaniment model of care. According to a study by Shin and colleagues, they found key factors that characterized their communitybased accompaniment program in the context of HIV care (Shin et al., 2010). This model was based on the stress-buffer theory for social support (Gore, 1981 and Cohen \& McKay, 1984). The Cinterandes mobile surgical program shares common factors which support our redefinition of Community-Based Surgical Care Accompaniment Model. In the following table (Table 2) we will look at community-based accompaniment factors described by Shin and we will focus on how Cinterandes incorporates each factors into their model of care. 
The Cinterandes' community-based surgical care accompaniment model has the power to overcome multiple barriers to surgical access including geographic, financial, social, and biosocial barriers. By bringing surgical care to the community, multiple social and health system disparity gaps are bridged. Cinterandes model of care is contained in one mobile surgical package in which surgical professionals, surgical and medical supplies, surgical infrastructure work together in a coordinated and effective manner. This model of care has been sustainable for 27 years. Moreover, Cinterandes mobile surgical team's solidarity is a key component for the success and sustainability of the program. All team members worked in unison with the common goal to provide timely, safe and high quality surgical care to the most vulnerable members of society, no matter how distant and remote was the community setting.

Table 3. Cinterandes Mobile Surgery's Community-Based Surgical Care Accompaniment Model

\begin{tabular}{|l|l|}
\hline $\begin{array}{l}\text { Community-based } \\
\text { Accompaniment Model } \\
\text { Social Support Factors }\end{array}$ & $\begin{array}{l}\text { How Cinterandes implements accompaniment factors into their } \\
\text { Community-Based Surgical Care Accompaniment Model of care }\end{array}$ \\
\hline Instrumental support & $\begin{array}{l}\text { Cinterandes coordinates with local healthcare providers or local community } \\
\text { stakeholders to organize and coordinate surgical missions so that patients } \\
\text { can access surgical care by contacting the local healthcare providers or } \\
\text { community stakeholders. Cinterandes is actively involved in making } \\
\text { surgical care readily available to rural patients. } \\
\text { By going to the community Cinterandes mobile surgery removes patient's } \\
\text { transportation barrier when seeking surgical care outside their local setting. } \\
\text { In addition, bringing surgical care inside the community prevents patients } \\
\text { abandon their personal responsibilities such as providing for the family or } \\
\text { working. Cinterandes provides the surgical supplies and medications } \\
\text { necessary for operative and post-operative care. }\end{array}$ \\
\hline Emotional support & $\begin{array}{l}\text { Informants highlighted the psychological and emotional benefit that mobile } \\
\text { surgery is able to accomplish. Patients experience less distress when being } \\
\text { cared for inside their communities with the support of their family members. }\end{array}$ \\
\hline Build trust of patients and & $\begin{array}{l}\text { Cinterandes builds patient's trust by achieving good surgical outcomes and } \\
\text { by showing long term commitment to communities. Cinterandes physician } \\
\text { home visits as well as engagement in socialización with rural patients build } \\
\text { trust. Rural patient's fears and concerns are addressed when Cinterandes } \\
\text { surgical care providers interact with patients during patient consult or home } \\
\text { visits. In addition patients expressed they became involved in efforts to } \\
\text { share with community member about their experience with mobile surgery } \\
\text { which creates trust in the mobile surgery program. }\end{array}$ \\
\hline
\end{tabular}




\begin{tabular}{|c|c|}
\hline Education & $\begin{array}{l}\text { Cinterandes provides education through surgical patient consults, primary } \\
\text { care consults, and engagement with patients through socializacion and } \\
\text { physician's home visits. They educate patients about surgical illness, the } \\
\text { surgical care process, what patients can expect when seeking care and the } \\
\text { importance to adhere to post-operative follow-up and care. }\end{array}$ \\
\hline Advocacy & $\begin{array}{l}\text { The Cinterandes Foundation has been advocating for equitable access to } \\
\text { surgery for rural, remote and vulnerable populations for at least } 27 \text { years } \\
\text { since the inception of the mobile surgery program. Cinterandes has invested } \\
\text { in the development of strong social and healthcare structures which support } \\
\text { mobile surgical care delivery. They collaborate with local community } \\
\text { leaders, local healthcare facilities, as well as private healthcare community } \\
\text { organizations to support their efforts to make surgical care accessible to the } \\
\text { most vulnerable in society. }\end{array}$ \\
\hline Improved adherence & $\begin{array}{l}\text { Cinterandes mobile surgery program has an established healthcare structure } \\
\text { to carry out pre-operative patient selection and post-operative patient } \\
\text { follow- up. Patients receive care since the pre-operative phase through the } \\
\text { post-operative phases. Cinterandes surgical patient follow-ups are at } 1 \\
\text { week, } 1 \text { month, } 6 \text { months and up to } 1 \text { year post-operatively. }\end{array}$ \\
\hline Resumed social roles & $\begin{array}{l}\text { Patients are able to recover quickly after undergoing an elective surgical } \\
\text { procedure in the mobile surgical unit. Patients go home on the day of the } \\
\text { surgery or the day after surgery. Post-operative recovery is then in the } \\
\text { patient's home, where the patient is able to assume social roles. The post- } \\
\text { operative patient is partially physically limited due to expected post- } \\
\text { operative physical recovery which takes place during days to weeks after } \\
\text { surgery. But patient is able to engage in some of their social roles. }\end{array}$ \\
\hline Increased self-efficacy & $\begin{array}{l}\text { Community based surgical care accompaniment equips patients to follow } \\
\text { post-operative care appropriately. This includes teaching patients how to } \\
\text { care for their surgical scar and how to take medication for pain control. } \\
\text { Patients are empowered by the Cinterandes care providers who instruct and } \\
\text { instill confidence in patient's ability to care for themselves after surgery. }\end{array}$ \\
\hline Hopefulness & $\begin{array}{l}\text { Multiple patients that received Cinterandes mobile surgery care reported a } \\
\text { positive emotional and psychological benefit from their interactions with } \\
\text { Cinterandes workers. Patient's distress about the incapacity that the surgical } \\
\text { illness caused them was removed They reported that another benefit of } \\
\text { obtaining a surgical procedure was a positive outlook on their futures. }\end{array}$ \\
\hline Reduced stigma & $\begin{array}{l}\text { Informants revealed that surgical illness was stigmatizing. Patients were } \\
\text { ashamed to disclose surgical illness to family member or friends. Informant } \\
\text { stated the surgical illness affected patient's self-image and perception of } \\
\text { self-worth and capacity. Surgical illness increased shame and reduced } \\
\text { patient's sense of capacity. Cinterandes timely surgical care delivery } \\
\text { mitigated stigma associated to surgical disease immediately. }\end{array}$ \\
\hline
\end{tabular}




\subsection{Recommendations for Surgical Stakeholders:}

The following recommendations have been developed to address the specific barriers and delays found in this study. We hope the reliability of the evidence provided, will help inform surgical stakeholders on their efforts to optimize surgical care delivery and increase access for rural populations.

\section{1) Build Surgical Capacity and Strategize Effectiveness in Surgical Care Delivery at Primary Level Hospitals and Primary Care Centers}

Hospitals of higher levels of care are often oversaturated with high surgical patient demands creating a surgical backlog (Meara et al., 2015). While patient accumulate, they have to wait long periods before they can be managed, especially in the cases of elective surgery. By building the effectiveness and surgical capacity at primary level hospitals and primary care centers, unnecessary referrals would be avoided and surgical demand at secondary and tertiary level hospitals would decrease.

Surgical capacity at primary level hospitals should be improved by ensuring that Bellwether procedureslaparotomy, caesarean section, and open-fracture repair - can be accomplished. These procedures have been classified as "acute high value procedures" because they are a measure of a facility's ability to carry out other essential procedures that are surgically complex (Meara et al., 2015). Moreover, the health system or each primary level hospital could standardize a list of surgical procedures that they can manage

effectively and with safety. These procedures must be done at the primary level hospital to ensure that all or most surgical cases that fall into that list are indeed managed at the primary level hospital. For example, low risk procedures like hernia repair, superficial soft tissue tumor resection or other medium risk procedures like cholecystectomy or intracranial hematoma evacuation can be potentially effectively managed at primary level hospitals (Meara et al., 2015) upon determination that a facility has the capacity to properly manage these conditions. Each primary level hospital should assess its capacity to manage specific conditions. Identification of specific conditions and enforcement to manage them with safety and 
efficacy at primary level hospitals, would avoid unnecessary referrals of simple manageable procedures to higher level hospitals.

The referral network between hospitals should also be revised and optimized to avoid oversaturation of higher level hospitals. Informants revealed patient referrals are not equally distributed among hospitals. Further studies need to be done to elucidate reasons behind why certain hospitals experience oversaturation. The referral system should be systematically and strategically optimized so that surgical care becomes decentralized into primary level hospitals which are closer to rural communities.

Having proper diagnostic tools is essential. The WHO found that over half of the world does not have access to radiology (Mollura et al., 2014). Basic blood laboratory and microbiology tests are not consistently available (Meara et al., 2015). Ultrasound and computed tomography are very important in emergency surgical management. It should be a priority to make these available at primary level hospitals. It is recommended to strategically invest in diagnostic imaging and laboratory equipment to accelerate the referral process and the effectiveness of patient management. If from the cost-effectiveness perspective, it is not feasible to equip all health centers with diagnostic tools, then the laboratory and imaging referral system should be revised because informants revealed frequent experiences bouncing back and forth between healthcare centers trying to obtain appropriate diagnostic tests, which was a significant factor for their delay in access to elective surgical care.

Surgical capacity needs to be optimized by increasing surgical hours of operation to cover 24 hour care and weekends. Strategies such as on-call services or task-shifting can be used. Surgical providers from higher level hospitals could consider rotating to primary level hospitals to cover for service deficits. If conditions can be safely and efficiently managed at primary level hospitals, rural patients should have greater access to surgical services. 
Services at surgical facilities should be timely. Since rural patients have to travel great distances to reach healthcare facilities, the system should help minimize the time a rural patient invests in being away from his/her community. Rural and indigenous populations are financially vulnerable (SIISE, 2017). Patients should be able to find a physician present when they are given an appointment. Physicians and surgeons should be on time to provide services. Some patient informants mentioned that they have encountered situations when a physician did not show up to the appointment because he/she was out of the office or on vacation, even though the patient has a confirmed appointment. Therefore, a clear system of communication needs to be established between healthcare providers and appointment centers so that patients are not waiting or investing their time, finances and effort towards appointment failures. Appointment times should also be respected so that patients spend less time away from their families. Timely services would encourage patients to seek surgical care earlier during non-complicated stages of the disease. Timely services at the primary care level and primary level hospitals would help avoid the flow of unsatisfied patients to the secondary level or tertiary level emergency departments.

In addition, we recommend the creation of professional development opportunities for physicians and surgical professionals to accurately diagnose and treat surgical conditions. Referrals to surgical facilities require an accurate surgical diagnosis properly documented. If the patient arrives to the surgical facility without this documentation, hospital surgical providers revealed this caused significant delays because patients will have to take steps back in the care seeking process. This would also contribute to the disorientation of rural patients in the referral process. Task-sharing between surgical professionals from higher level hospitals with surgeons at primary level hospitals, would help promote the development and maintenance of high level surgical skills. 
In addition, it was strongly recommended by informants, that each hospital should hire one or two professionals to specifically manage and monitor the hospital's supply chain procurement. Due to the complexities of the new centralized ordering processes, there are multiples steps where delays may potentially occur. Not having surgical supplies on time or availability of medications may result in the postponement or cancellation of surgeries. Therefore, hospitals need a professional to exclusively handle the timely arrival of supplies and avoid stock-outs.

\section{2) Establish Amending structures}

It is recommended that the state and healthcare system should invest in reconciliation efforts with rural populations to restore trust in the government and public healthcare. Improving access to surgical care in rural communities would improve their health, strengthen rural communities and amend the broken relationship between the state and rural people which developed through years of colonialism and structural violence. The development of amending healthcare structures could help bridge the social gap between the rural patients and the public healthcare by attract rural populations to public healthcare services and promote trust in the public system.

\section{a) Institutionalize Socialización in the Rural Healthcare System.}

Socialización can be used in outreach efforts by the health system to integrate rural communities into the public surgical system. The institutionalization of socialización practices between physicians or surgeons and rural patients can bridge knowledge gaps by providing surgical and health education, thereby reducing fears about surgery, promoting surgical care seeking behavior and most importantly amend longstanding rural social disparity. Through socialización trained healthcare providers can address the fears that rural patients have about the health system. In addition, socialización can be used to address patient's shame when they interact with surgical providers through the provision of information and 
expectations in the surgical care seeking process. Overall, socialización can help develop rural patient trust in the public health system which would contribute to build a good reputation for the health system.

\section{b) Incorporation of Cinterandes Mobile Surgery Model into the National Surgical Delivery System}

The Cinterandes mobile surgery program brings surgical care inside rural communities. This model unites all the necessary components of effective surgical care delivery including the necessary surgical staff, the surgical infrastructure, surgical supplies as well as surgical expertise to manage low risk surgical cases. Cinterandes mobile surgery is effective to treat people in rural and remote settings (Shalabi, 2017).

By bringing care to the community, multiple barriers and delays are overcome. Rural patients do not have to travel to urban health facilities thereby avoiding the fear, threat, and intimidation of unfamiliar settings. When surgical care is brought to the community the rural patient does not need to separate from his family unit for extended periods. Pre-operative preparation is done remotely with a healthcare liaison between the rural community and the Cinterandes program. This is used to establish a potential surgical diagnosis and to ensure that appropriate tests are obtained prior to Cinterandes arrival to the community. Then, once Cinterandes has arrived to the community to provide surgical services, only one consultation is needed prior to surgery to confirm surgical diagnosis, low-risk of surgery and ensure pre-operative patient preparation. These two processes minimize the time patient are away from their families and responsibilities. In addition, surgical care in the community is beneficial because the family is involved in the post-operative care. It helps obtain good clinical outcomes as well as faster immediate post-operative recuperation. Mobile surgical care provides good patient outcomes and could alleviate costs of the healthcare system by avoiding extended stays in hospitals. 
In addition, Cinterandes uses socialización to break-down barriers of distrust in the healthcare system. It has been documented that Cinterandes surgical care has the capacity to gain trust in rural communities (Shalabi, 2017). The Cinterandes team interacts with rural communities with respect, compassion, and provides high quality care. Every team member clearly informs patients about the surgical illness, the surgical process, risks associated to surgery as well as risks of not obtaining surgical management. All information is provided so that the patient is empowered to have agency and make an informed decision about surgery. This form of interaction with rural patients and surgical providers is very effective at removing fears about surgery care, surgeons, and distrust in the healthcare system. When socialización is combined with good surgical outcomes, the mobile surgical care system has the ability to propagate trust throughout the community and even to other neighboring communities through word of mouth. According to Cinterandes surgeons, they have encountered that people from settings or greater remoteness will make their way to Cinterandes' location because they have heard about the good surgical outcomes.

Mobile surgery could be used as a tool to build surgical capacity in rural settings. Healthcare structures need to be built to increase access for rural populations. Mobile surgery may be an effective intermediary model until primary level hospitals can gain full surgical capacity. This surgical care model can be used to extend the reach into communities that live in isolation by geographical and biosocial barriers.

In addition, surgical capacity is not optimal at primary level hospitals which are closer to rural settings. Mobile surgery may play an important role in building surgical capacity at primary level hospitals or rural healthcare centers. Mobile surgery can be used to optimize accurate surgical diagnosis, through training and collaboration with rural physicians in primary healthcare settings.

Institutionalizing the Cinterandes mobile surgery model into the public healthcare delivery system, would create a public healthcare structure that would help amend social inequalities and structural violence 
experienced by rural populations. Providing a system that is at greater reach for rural and remote communities, would be as an act of commitment of the state and public healthcare system to rural society's health, well-being and social development. Through community-based mobile surgical care and accompaniment, the violence of colonialism can be mitigated, and replaced by a social structure characterized by solidarity with the rural populations.

We recommend for the Ecuadorian government and Ministry of Health officials to consider the reignition of the country's mobile surgery program to leverage surgical capacity across the country and decrease the burden of unmet surgical disease. As revealed in this study, Ecuador already possesses mobile surgery infrastructure — about 7 mobile surgical units — that are not being used or are underutilized. The government, in collaboration with the Cinterandes Foundation, has the opportunity to become a world pioneer of a national scale mobile surgical program. The Cinterandes Foundation has expressed their will to deepen collaboration with the government and Ministry of Health. Ecuador is living through an important time in which its contribution through a national scale-up of mobile surgery can set the example for other Latin America and developing nations.

c) Discontinue Discourse of Ethnically-Related Surgical Care Seeking Behaviors because it May Act as a Barrier to Surgical Care Access

This study proved that the general assumption about rural population's preference for traditional medicine over allopathic medicine is false. Patients do not seek traditional medicine as the first option to treat a surgical illness. Informants stated that they understood that a surgical illness required a surgical solution. Patients were open to seek surgical care and preferred it over traditional medicine. Healthcare providers, leaders and workers should discontinue the perpetuation of the idea that traditional medical practices are a main cause for surgical access delays. By promoting the assumption that delays are mostly a consequence of rural patient's behavior or cultural beliefs, the patient becomes the main agent 
responsible for the delay. The evidence in this study shows that delays in care seeking involve other factors such as, the existence of inadequate healthcare structures and even social disparities. Placing responsibility on patients prevents surgical stakeholders from objectively considering delays in the health system. We cannot use this discourse - that is based on ethnic differences - as justification for patient delays. Not addressing health-system factors will perpetuate patient suffering and subjugation of rural people to chronic surgical illnesses.

\section{d) Institutionalize Home Visits by Rural Physicians or Surgeons}

Consider the institutionalization of home visits to rural patients as part of the health care system. Home visits have the power to break barriers among rural patients. They help overcome social barriers that have historically divided the rural society from the health system. Physician or surgeon home visits contribute to early detection of surgical illnesses that often become chronic and complicated. This new implementation can potentially avoid accumulation of complicated surgical patient presentations at the hospitals, and may also contribute to reducing costs by the health system associated to treatment and transport of complicated surgical cases.

Home visits may be cost-effective since the healthcare system may be able to avert costs of treating complicated emergency surgical cases at advanced level hospitals. Cost-effectiveness analysis would be recommended to study this topic. Home visits could help avoid accumulation of surgical cases at higher level urban hospitals. It would help minimize the need for rural patients to be transferred to secondary and tertiary level hospitals. Home visits are also an opportunity to encourage reluctant rural patients to seek care at public surgical facilities.

This requirement should not be imposed on overburdened rural physicians without supplying a supportive healthcare structure. Consider that mobile surgery is a feasible model in which surgeons and physicians would be able to make home visits with greater ease. 


\section{e) Examine Financial Incentives as a Possible Facilitator for Seeking Surgical Care at}

\section{Urban Settings}

Rural patients face financial barriers to seeking surgical care. With over $50 \%$ of the rural population livings in poverty (SIISE, 2017), it would be socially responsible to provide financial aid to seek surgical care. Rural populations may require a financial incentive so they can have the capacity to seek surgical care at distant urban hospitals. This could offset the financial loss that patients endure from not being able to work and create income for the family while engaging in care seeking.

\section{f) Policy Change to Expand Availability of Surgical Services to Rural Communities}

The following recommendations are intended to reduce the volume of unnecessary surgical patient referrals to secondary and tertiary level hospitals. We must address unmet surgical burden, decrease delays in surgical care and decrease patient suffering.

The state should grant decision making power to local hospitals. Local healthcare structures may need to be adapted to meet local needs. The healthcare system should change the strict policy of hiring surgeons only by 8 hour shifts. Access to surgical care should be made available 24 hours a day, seven days a week at all hospitals. On-call surgical services should be leveraged to make surgical, anesthesia and allied professionals, available outside regular day business hours.

Policy makers need to strategize how to improve access to surgical care for remote communities. As seen in this study, the care seeking trajectory of patients from remote settings is difficult and exhausting. It has been reported that surgical patients travel by foot over multiple days to traverse difficult terrain like the Amazon forest. In areas where road construction or transportation systems have not been well developed, 
patients are at greater risk of death, complication and financial catastrophe if faced with the need of surgical care. We suspect that they may be other remote communities in the Andes or coast as well. We must work to decrease patient isolation. Therefore, the need to address the surgical needs or people in remote settings should strongly highlight the great importance of the Cinterandes' community-based surgical care and accompaniment model. This model of surgical delivery would be very feasible for remote settings.

\section{g) Provide Tools to Help Rural Patients Navigate the Healthcare System Effectively}

If patients are required to seek care at large urban hospitals, the system should provide tools designed to help rural patients navigate the hospital. For example, hospital information booths could provide materials in common indigenous languages like Kichwa and Shuar or an information agent should provide instructions in native indigenous languages. If a patient is illiterate, the hospital should provide a visual navigation guide specifying the steps the patient must take to effectively seek care at the hospital.

Informants mentioned the difficulties rural patients experience when trying to obtain an appointment using technology. The shortcomings of the telephone and internet appointment systems need to be addressed. Because rural patients are less likely to have access to telephones and internet, the healthcare system should offer an alternative option to make appointments, such as in-person appointment desks at health centers, or making telephones and computers available at health clinics with adequate guidance on how to use these tools to make appointments.

\section{h) Information and Guidance Should be Delivered Clearly and Respectfully during Every Step of the Surgical Care Process}

This study has established that fears of hospitals, surgeons, surgery and related procedures are associated with the unfamiliarity of rural patients with the health system and misinformation. Therefore, at every 
step of healthcare and surgical delivery process, patients should be provided with information with clarity and respect. Because unfamiliarity as well as negative interpersonal interactions with healthcare providers discourage rural patients from seeking care, this is an important modifiable factor. Equipping patients with clear information as well as treating rural patients with empathy can be powerful tools to avoid their delays in seeking surgical care.

\section{LIMITATIONS}

This study was limited by the sample number of participants. We had a total of 36 informants who were distributed among different category groups including: hospital patients, Cinterandes patients, non-treated patient, hospital healthcare providers and workers, Cinterandes healthcare providers and workers, and leaders which included healthcare leaders and community leaders. The number of patients among the patient groups varied. Hospital patients were five, Cinterandes patients were nine, and non-treated patient was one. This may have affected the analysis of the types of responses provided by patients. It was particularly challenging to identify non-treated surgical patients.

\section{CONCLUSION}

Our study found the existence of a spectrum of complex biosocial barriers affecting health system effectiveness at delivering surgical care and rural patient's ability to access care. Through a comprehensive biosocial analysis, we have gained in-depth understanding why these barriers exist and persist. Health system-centered delays were related to the centralization of decision making power, inefficiencies of the healthcare system, government's strong regulations on non-governmental organizations, the lack of supplies negatively impacting delivery of surgical care, and the false assumptions about rural patient's use of traditional medicine. Other patient-centered barriers included

patients' distrust in public services - contextualized by a long history of colonialism, discrimination and 
hostility between government and rural indigenous populations; unfamiliarity with hospitals, doctors and urban settings; the responsibility patients assume to care for the family; and the unique remoteness of rural communities like those found in the Amazon. Historical, social, political and economic structures have contributed to the development of structural violence which encompass barriers and affect the livelihood and health of rural communities.

To optimize surgical access and improve surgical outcomes we can draw from the positive effects that the maintenance of the family unit has on the patient, as well as the barrier-mitigating-effects of socialización and home visits by surgeons or doctors can have on rural communities. The specific recommendations should be strongly considered by surgical stakeholder to bridge surgical access disparity gaps. Strong evidence reveals that increasing the effectiveness and building surgical capacity at primary level hospitals and primary healthcare centers is fundamental. The development of amending healthcare structures to improve access to care is of utmost importance to reconcile rural patient's interactions with the public healthcare system and the state. Cinterandes' model of community-based surgical care accompaniment program promises to reap safe and cost-effective expansion of surgical care access. Policy changes pertaining to surgical services, development of tools that are culturally appropriate for improved communication with rural patients, and the delivery of care that strives to inform patients through respect and empathy, are necessary to ensure high quality surgical delivery.

Access to surgical care is a human right (Farmer, Kim 2008). Ecuador has the opportunity to invest in its social capital through surgical expansion. Cinterandes mobile surgery has proved to be a practical and feasible model of surgical delivery that can address biosocial barriers and delays at multiple levels. It would be a benefit to society for Ecuador's government and the Cinterandes Foundation to joint efforts in reigniting the country's mobile surgical program and leverage surgical capacity. 


\section{REFERENCES}

Alchon, S. (1991). Native society and disease in colonial Ecuador. New York: Cambridge University Press.

Al Jazeera (2010). People and Power - Ecuador: Water or Gold. Sept 13, 2010. https://www.youtube.com/watch?v=obE-BmonWRQ

Asamblea Constituyente (2008). Constitución de la República del Ecuador. Registro Oficial Número 449. http://www.asambleanacional.gob.ec/sites/default/files/documents/old/constitucion de bolsillo.pdf

Astudillo, G. (2016). El Comercio. El salario mínimo de Ecuador paso de USD 160 a 366 en 10 años. December 14, 2016. http://www.elcomercio.com/actualidad/salariobasicounificado-salariominimoecuador-inflacion.html

Atiyeh, B.S., Gunn S.W., \& Hayek S.N. (2010). Provision of essential surgery in remote and rural areas of developed as well as low and middle-income countries. International Journal of Surgery, 8:581-5

Barnes-Josiaha, D., Mynttib, C., \& Augustino, A. (1998) The "three delays" as a framework for examining maternal mortality in Haiti. Social Science and Medicine, 46(8):981-99.

Bass, M., Finer, Jenkins, C. N., Kreft, H., Cisneros-Heredia, D., McCracken, S., Pitman, N., English, P., Swing, K., Villa G, Di Fiore, A., Voigt, C., \& Kunz, T. (2010). Global Conservation Significance of Ecuador's Yasuní National Park. PLOS One Peer Review Journal. 5(1): e8767. Doi:

10.1371/journal.pone.0008767

Byrne, G. (2015, Jan 7). CONAIE Headquarter to be shut down: indigenous peoples of Ecuador request international support. Sociology Lens. Accessed April 15, 2017. Retrieved from http://scholar.aci.info/view/1487aa7d42b6f920132/14ad6f95ead074b014d

Cavallo, S. (2016). Forced sterilization of 272,000 indigenous women 'not a crime against humanity': public prosecutor. Open Democracy, Sept 13. https://intercontinentalcry.org/forced-sterilization272000-indigenous-women-not-crime-humanity-public-prosecutor/

Ceaser, M. (2006). Taking surgical services to rural Ecuador. World Report, 368:1563

Chao, T.E., Sharma, K., Mandigo, M., Hagander, L., Resch, S.C., Weiser, T.G., \& Meara, J.G. (2014). Cost-effectiveness of surgery and its policy implications for global health: a systematic review and analysis. TheLancet Global Health. 2(6):e334-45

Cinterandes (2017). Cinterandes Vision. Retrieved from http://www.cinterandes.org/index.php/en/home

Cohen, S., \& McKay, G. (1984) Social support, stress, and the buffering hypothesis: a theoretical analysis. Handbook of Psychology and Health (pp. 253-267). Erlbaum, Hillsdale, NJ: A. Baum, J.E. Singer \& S.E. Taylos 
Conaghan, C.M. (2016). Delegative Democracy Revisited: Ecuador Under Correa. Journal of Democracy. 27(3), 109-118.

CONFENAIE. Cultural Survival Quarterly (2012). 36(3): 8-9.

Constante, Soraya (2013, Dec 11). Ecuador cierra una ONG que respaldaba la lucha antipetrolera en el Amazonas. El Pais,

Cuenca High Life (2015, Feb 16). Correa proposes new rules, new management for Ecuador's social security system; expats using IESS health care services could be affected.

Davalos, P. (2014). Alianza PAIS o la reinvención del poder: siete ensayos sobre el posneoliberalismo en el Ecuador. Colombia: Ediciones desde abajo

De Paepe, P., Echeverria, R., Aguilar, E., Unger, J.P. (2012). Ecuador's silent health reform. International Journal of Health Services, 42, (2), 219-233. Doi: http://dx.doi.org/10.2190/HS.42.2.e

Dea Macanilla, S. (2009). Se acabaran los cedros, nosotros no. Autobiografía de un naporuna. Quito: CICAME.

Debas, H., Gosselin, R., McCord, C. (2006). Surgery. In: Disease control priorities in developing countries, $2^{\text {nd }}$ edn. NY: Oxford University Press.

Democracy now (2014). Murder of Shuar leader USA Democracy Now headline news broadcast. Retrieved from https://www.youtube.com/watch?v=Zip2wN31EOo

Ecuador Government (2011). Ecuador Yasuní ITT: Manual de Procedimientos para el Funcionamiento del Comité de Dirección.

Erazo, P.M. (2013, Aug.16). Porque fracasó el proyecto ambiental del Yasuní en Ecuador. BBC.

Falkingham, J. (2004). Poverty, out-of-pocket payments and access to health care: evidence from Tajikistan. Social Science and Medicine, 58(2), 247-258. doi.org/10.1016/S0277-9536(03)00008-X

Farmer, P. (1998). Pathologies of power: rethinking health and human rights. American Journal of Public Health, 89(10), 1486-1496.

Farmer, P. (2004). An Anthropology of Structural Violence. Current Anthropology, 45(3): 305-325

Farmer, P.E., \& Gutiérrez G. (2013). In the company of the poor: conversations with Dr. Paul Farmer and Fr. Gustavo Gutiérrez. New York: Orbis Books

Farmer, P.E., \& Kim, J.Y. (2008). Surgery and global health: a view from beyond the OR. World Journal of Surgery, 32: 533-36

Gore S. (1981) Stress-buffering functions of social supports: an appraisal and clarification of research models. In: B.S. Dohrenwend \& B.P. Dohrenwend (Eds) Stressful Life Events and Their Contexts, pp. 202-222. Prodist, New York. 
Grimes, C.E., Law, R.S.L., Borgstein, E.S., Mkandawire, N.C.,\& Lavy C.B. (2012) Systematic review of met and unmet need of surgical disease in rural sub-Saharan Africa. World Journal of Surgery, 36:823.

Hagensli, N., Stenvik, A., \& Espeland, L. (2014). Patients offered orthognathic surgery: why do many refrain from treatment? Jounal of Cranio-Maxillofacial Surgery, 42(5): e296-300.

Holmer, H., Lantz, A., Kunjumen, T., Finlayson, S., Hoyler, M., Siyam, A., Montenegro, H., Kelley, Et., Campbell, J., Cherian, Mn. \& Hagander, L. (2015). Global distribution of surgeons, anaesthesiologists, and obstetricians. Lancet Global Health,3, Suppl 2: S9-S11.

Hutubessy, R., Baltussen, R., Tan-Torres, T., \& Edejer, E. D. (2003). Generalized cost-effectiveness analysis: an aid to decision making in health, World Health Organization, Geneva.

Instituto Nacional de Estadistical y Censos (INEC) (2010). Resultados del Censo 2010 de Población y Vivienda en el Ecuador. Poblacion y Demografia. Retrieved from http://www.ecuadorencifras.gob.ec/censo-de-poblacion-y-vivienda/

Johnson ,T., Gaus, D., \& Herrera, D. (2016). Emergency Department of a Rural Hospital in Ecuador. Western Journal of Emergency Medicine, 18(1):66-72.

Kelly, N. (2012). When the Pen Is Mightier Than the Sword: A Shuar Poet Redefines Her.

Kim, J. (2016, July 15). Preferential option for the poor in Healthcare (Oral presentation). Partners in Health Headquarters, Boston, MA.

Koenig, K. (2017). Community Consent: business lessons from the Amazon. Amazon Watch. Retrieved from http://amazonwatch.org/news/2017/0323-community-consent-business-lessons-from-the$\underline{\text { amazon }}$

Kohler, P.K., Ondenge, K., Mills, L.A., Okanda, J., Kinuthia, J., Olilo, G., Odhiambo, F., Laserson, K.F., Zierler, B., Voss, J., \& John-Stewart, G. (2014). Shame, Guilt, and Stress: Community Perceptions of Barriers to Engaging in Prevention of Mother to Child Transmission Programs in Western Kenya. Aids Patient Care and STDs, 28(12), 643-651. Doi: 10.1089/apc.2014.0171.

Kushner, A., Cherian, M., Noel, L., et al., (2010). Addressing the millennium development goals from a surgical perspective: essential surgery and anesthesia in 8 low-and middle-income countries. Archives of Surgery, 145(2): 154-9.

Larrea, C. \& Montenegro-Torres, F. (2006). Chapter 4 Ecuador. Indigenous Peoples, Poverty and Human Development.NY: Palgrave Macmillan.

Lee, A. (2013). Global Health and the Surgeon 2013 Runner-Up Abstract-Challenges and Training Opportunities in Voluntary Surgery-Perspectives from an Operation Hernia Mission in Rural Ecuador. Annals of Medicine and Surgery, 2(1): 39. 
Ling, J. (2017, Jan). Blood and fire: mining and militarization in the Ecuadorean Amazon. Retrieved from https://www.counterpunch.org/2017/01/26/blood-and-fire-mining-and-militarization-in-theecuadoran-amazon/

Living Conditions Survey, (1998). National Institute of Statistics and Censuses (Ecuador) 10/1998 to 09/1999. Retrieved from http://ghdx.healthdata.org/record/ecuador-living-conditions-survey-19981999

Macmillan, P. (2006). Indigenous People, Poverty and Human Development in Latin America. 1994-2004 Editors Guillete Hall and Harry Anthony Patrinos. Retrieved from https://elibrary-worldbank-org.ezpprod1.hul.harvard.edu/doi/pdf/10.1596/978-1-4039-9938-2

Mancia, G., Parati, G., Pomidossi, G., Grassi, G., Casadei, R., \& Zanchetti, A. (1987) Alerting reaction and rise in blood pressure during measurement by physician and nurse. Hypertension, 9(2):209-215

McQueen, K., Ozdegiz, D., Riviello, R. et al. (2010) Essential surgery: integral to the right to health. Health and Human Rights Journal. 12(1): 137-152.

Meara J, Leather A, Hagander L, et al. (2015). Global Surgery 2030: evidence and solutions for achieving health, welfare, and economic development. The Lancet, 386 (9993):569-624.

Ministerio de Salud Pública (MSP) (2014, Dec 24). Tarifario de Prestaciones Para el Sistema Nacional de Salud. Edición Especial No 235 - Registro Oficial, Quito. p 1-336.

Mollura, D. J., Shah, N., Mazal, J., RADAIDCW Group, the RAD-AID Conference Writing Group (2014). White paper report of the 2013 RAD-AID Conference: improving radiology in resourcelimited regions and developing countries. Journal American College of Radiology, 11: 913-919

Myles, P.S., \& Haller, G. (2010). Global distribution of access to surgical services. The Lancet, 376 : 1027-1028.

Nash, D. (2014, Dec. 1). On the Symbolism of the White Coat. Journal of Dental education., 78(12), 1589-1592.

Nead, J. (1999). Promote healthcare's humane environment. Nursing Management. 30(9), 41

OSAC (2017). Ecuador 2017 Crime \& Safety Report: Guayaquil. Retrieved from https://www.osac.gov/Pages/ContentReportDetails.aspx?cid=21083

Ozgediz, D., Jamison, D., Cherian M., \& McQueen, K. (2008) The burden of surgical conditions and access to surgical care in low- and middle-income countries. The Bulletin of the World Health Organization, 86(8), 646-647.

PAHO/WHO (2008, Dec 9-11). Joint Meeting of the PAHO/WHO/Ministry of Health of Integrated Management for Emergency and Essential Surgical Care, Quito Ecuador. Retrieved from http://www.who.int/surgery/education_training/Ecuadorworkshopreport.pdf 
Parati G., Ochoa, J.E., Lombardi, C., \& Bilo G, (2014) White Coat Hypertension: Definition, Terminology and Prevalence. White Coat Hypertension. p. 1-19. Retrieved from https://link-springercom.ezp-prod1.hul.harvard.edu/chapter/10.1007/978-3-319-07410-8_ 1

Patton, M. Q. (2015). Qualitative research \& evaluation methods : integrating theory and practice. California : SAGE Publications.

Perkins, J. (2001, July 1). Spirit of the Shuar: Wisdom from the Last Unconquered People of the Amazon.

Petersson, C. (2012). Negotiating Reproduction: Family Size and Fertility Regulation among Shuar People of the Ecuadorian Amazon. SwePub . p 153-180.

Puente, D. (2017, March 22). El papel de las organizaciones en la agenda de los presidenciables. El Comercio. www.elcomercio.com/tag/decreto-16a

Radio Canela 103.7 Macas (2016, Aug. 13). Destruyen todas las viviendas de los Shuar en Nankints para entregar a minera China. Retrieved from https:/www.youtube.com/watch?v=7Fv210q7-Fk

Radio Canela 103.7 Macas (2016, Aug. 14). Operativo militar policial en la comunidad de Nankints. Retrieved from https://www.youtube.com/watch?v=JiymyHh7gMg

Ramirez, F. (2017, Feb 28). Ecuador is Divided Over its Political Future. US News.

Rodas, E., Vicuña, A. \& Merrel, R.C. (2005). Intermittent and Mobile Surgical Services: Logisticsand Outcomes. World Journal of Surgery, 29(10):1335-1339.

Rojas, N. (2013, August). El decreto ejecuto No. 16 que controla a las organizaciones sociales. Ecuador Libre Red. Retrieved from https://www.youtube.com/watch?v=NjtHs-qOgUI

Rose, J., Chang, D.C., Weiser, T.G., Kassebaum, N.J., \& Bickler, S.W. (2014). The role of surgery in global health: analysis of United States inpatient procedure frequency by condition using the Global Burden of Disease 2010 framework. PLoS One, 9: e89693.

Rudel T (1989). Resource Partitioning and Regional Development strategies in the Ecuadorian Amazon. Geo Jounal. 19(4), 437-46.

Shalabi, H.T., Price, M.D., Shalabi, S.T., Rodas, E.B., Vicuña, A.L., Guzhñay, B., Price, R.R., \& Rodas, E. (2017). Mobile gastrointestinal and endoscopic surgery in rural Ecuador: 20 years' experience of Cinterandes. Surgical Endoscopy Doi 10.1007/s00464-016-4992-9

Seely, M. (2010). The Most Distant Places: a small team of determined doctors expanding the possibilities of rural health for their own people. Open Signal Productions.

Shrime, M.G., Bickler, S.W., Alkire, B.C., Mock, C. (2015). Global burden of surgical disease: an estimation from the provider perspective. Lancet Global Health, 27;3 Suppl 2:S8-9. Doi:

10.1016/S2214-109X(14)70384-5. 
SIISE Sistema de Indicadores Sociales del Ecuador (2017). Pobreza por necesidades básicas insatisfechas (NBI). Ministerio Coordinador de Desarrollo Social. Retrieved from http://www.siise.gob.ec/agenda/index.html?serial=13

The World Bank (2016). Poverty overview. (Accessed 8/12/17). Retrieved from http://www.worldbank.org/en/topic/poverty/overview

Vidal, J. (2016). Oil drilling underway beneath Ecuador's Yasuní National Park. The Guardian.

WHO. Traditional medicine strategy 2002-2005. Retrieved from http://www.wpro.who.int/health technology/book_who traditional_medicine_strategy_2002 2005.pdf

Wolf, H.T., Halpern-Felsch, B., Bukusi, E., Agot ,K.E., Cohen, C.R., \& Auerswald, C.L. (2014). "It is all about the fear of being discriminated [against]...the person suffering from HIV will not be accepted": a qualitative study exploring the reasons for loss to follow-up among HIV-positive youth in Kisumu, Kenya. BMC Public Health, 14:1154.

World Health Organization (2014). Ecuador Statistical Country Profile, Retrieved from http://www.who.org

Zamkovaya, N. (2014). About Some Aspects of "Colonial Racism". The Russian Academic journal, 29(3) 


\section{Appendices: Interview Guides}

\section{Appendix 1 \\ Semi-Structured Interview Guide for Patients \& Participants}

\section{Introduction:}

1. Do you live in a rural community?

a. If so, can you briefly describe your community?

b. What job do you do?

2. Please, tell me about your medical condition.

\section{Assessing the Three Delays:}

3. When did your symptoms start?

4. Have you searched for help for your problem?

a. If yes:

i. When did you seek help for the first time?

ii. What help did you seek? (family, traditional healer, doctor, clinic, etc.)

iii. Why did you wait this time to seek help?

5. Did you go to a doctor?

a. If so, specify the type of doctor and where.

b. When did you arrive to the doctor?

c. Why did it take this time to arrive to the doctor?

d. What did the doctor do for you? (i.e. diagnosis? or treatment?)

6. Have you reached a hospital for your surgical condition?

a. If yes

i. When?

ii. Why did it take this time (time between the first and second delay) to arrive at a hospital?

b. If not,

i. Why have you not reached a hospital?

7. Are you seeking/sought care with a surgeon?

a. If yes...

i. At what facility are you seeking/did you seek a surgeon?

1. Was this at the first hospital you reached?

ii. Have you seen a surgeon here?

1. If so, when?

iii. What treatment has been provided? 
b. If not... why not?

8. Have you received a surgery for your condition?

a. If yes...when?

b. Why did it take time between reaching the first hospital and receiving the surgery?

c. If not...

1. Why not?

2. Do you have a scheduled surgery?

If yes...When?

If not...Why not?

9. Has your surgical condition been resolved?

a. If not, why not?

10. Have you had any complications?

a. If so, please explain.

11. Did you experience any difficulties in accessing surgical care at the hospital because supplies were not available? Please explain.

12. Did you experience any difficulties in accessing surgical care at the hospital because the surgical/medical staff was not available? Please explain.

\section{Care Seeking Experience:}

13. Please, can you describe what your experience has been like seeking surgical care?

14. Can you describe good things about the surgical care system that you have access to? (Please explain and specify which system you are referring to)

15. Can you identify obstacles (barriers, delays) you have experienced in trying to access surgical services? Please explain.

16. Are you satisfied with the surgical service you have received/are receiving at the hospital: please explain why? Or why not?

\section{For Cinterandes Patients:}

a. How did you arrive at Cinterandes?

b. Please describe your experience seeking surgical care at Cinterandes.

c. Why did you decide to pursue surgical care at Cinterandes mobile surgery?

d. What would you prefer, to receive surgical services at a hospital or at Cinterandes mobile surgery? Please explain your reason

e. Can you describe what you think is good about surgical care at Cinterades mobile surgery? Please explain 
f. Can you identify obstacles (barriers, delays) you have experienced at Cinterandes? Please explain.

g. Did you experience any difficulties in accessing surgical care at Cinterandes because supplies were not available? Please explain.

h. Did you experience any difficulties in accessing surgical care at Cinterandes because medical staff was not available? Please explain.

i. Are you satisfied with the surgical care you have received/are receiving at Cinterandes? Please explain why? Or why not?

\section{How to optimize the system?}

18. In your opinion, what needs to be done in order to improve access to surgical care for people living in rural/distant town?

a. Please explain.

b. What aspects would you keep the same?

c. What aspects would you change?

19. Is there anything that you would like to communicate to the following people in order to optimize surgical care access?

a. To your physician

b. To your surgeon/anesthesiologist/healthcare workers

c. To your hospital leader

d. To your local healthcare/community leader

e. To your government officials

\section{Impact:}

20. Has your surgical condition affected you socially?

a. If so, how? (i.e. your family, work, social environment)

21. Has your surgical condition affected you mentally or emotionally?

a. If so, how?

22. Has your surgical condition affected you financially?

a. If so, how?

\section{Conclusion:}

23. Is there anything you would like to add to help us understand the barriers and delays you face in order to access to surgical care?

24. Is there anything you would like to add to help us understand how to optimize the surgical care system for patients in rural settings?

25. Do you have any additional comments?

\section{Thank you for your time.}




\section{Appendix 2 \\ Semi-Structured Interview Guide for Healthcare Provider/Worker}

1. What is your profession/healthcare position?

a. Where do you work?

b. What type of hospital/clinic is it?

c. What is your specialty/

d. How long have you worked there?

2. Tell me about your experience working as a healthcare provider/worker in your local setting?

3. What do you think of the current state of surgical care in rural settings?

4. What is your opinion on services provided by your hospital to the rural patient?

5. Do you serve rural populations? If yes...

a) How would you compare the needs of surgical rural patients to urban patients?

b) Can you identify barriers/delays that rural patients face

a. To decide to seek care?

b. To arrive to a hospital/facility that provides surgical care?

c. After patient arrives to hospital/facility, can you identify barriers/delays rural patients confront before they can finally receive their surgery?

d. Are there any other barriers or delay that may keep the patient from solving their surgical problem quickly?

6. What barriers do you face as healthcare provider/worker in your hospital/facility which delay timely surgical care? Please explain.

7. What area/s within your hospital/surgical facility could work more effectively to provide timely care to the rural patient? Please explain.

8. Can you identify key stakeholders that could optimize the surgical care system

a. Such as:

i. In your hospital?

ii. Healthcare leaders, community leaders, government officials?

b. What would they need to do?

9. How does the state/government collaborate for the provision of surgical care?

a. What aspects of the government healthcare system work well for the rural surgical patient?

b. What barriers exist in the government healthcare system that may keep patients from timely access to surgical care?

10. How can the government optimize collaboration with surgical institutions to improve surgical care access for the rural patient?

11. Do you think private institutions, like NGOs can help improve the surgical system?

a. If so, how should they work to optimize services for the rural patient? 
12. What do you think of mobile surgery?

13. Do you see mobile surgery as a feasible way to help improve surgical care delivery for rural patients? Explain.

14. As a healthcare provider/worker can you identify a way/s in which you can directly help optimize surgical care access for rural patients?

a. What would that be?

b. How would you do it?

15. Is there anything else you would like to add that would help us understand barriers and delays rural patients confront in accessing surgical care?

16. What else would you like to add to help us understand how to optimize the surgical care system and access to care for rural patients?

17. Are there any other additional comments you would like to add?

Thank you for your time 


\section{Appendix 3 \\ Semi-Structured Interview Guide for Cinterandes Healthcare Provider/Worker}

18. Do you want your position as healthcare/community leader to be identifiable?

i. If yes

1. What is your position/profession in healthcare?

2. What is your specialty?

3. Where do you work?

4. How long have you worked there?

19. Tell me about your experience working in Cinterandes.

20. What is the role of Cinterandes mobile surgery?

21. How does Cinterandes mobile surgery work?

22. What do you think of the current state of surgical care delivery for rural patients?

23. Do you serve rural populations?

24. If yes...

c) How would you compare the needs of surgical patients from rural settings compared to patients from urban settings?

d) Can you identify barriers/delays that rural patients face in seeking care?

e) Can you identify barriers/delays that rural patients face in reaching care?

f) Can you identify barriers/delays that rural patients face in receiving care?

25. What are the challenges that mobile surgery faces in trying to provide surgical care?

26. Do you face barriers/challenges as healthcare provider/worker to provide timely surgical care? Please, explain.

27. Can you identify areas within the state surgical care system that can become more effective in delivering care to rural patients?

a. If so, please explain how?

28. Does Cinterandes work with the government?

a. If so, how? 
29. Do you think mobile surgery can be expanded in Ecuador? Please explain.

30. Can surgical care access be optimized for rural patients?

a. What would that be?

b. How would you do it?

31. Is there anything else you would like to add that would help us understand barriers and delays rural patients confront?

32. Is there anything else you would like to add that would help us understand how to optimize surgical care access for rural patients?

33. Are there additional comments you would like to mention about Cinterandes?

34. Do you have any other comments you would like to add?

Thank you for your time. 


\section{Appendix 4 \\ Semi-Structured Interview Guide for Healthcare/Community/Government Leader}

1. Do you want your position as healthcare/community leader to be identifiable?

i. If yes

1. What is your position/profession in healthcare?

2. Where do you work?

3. How long have you worked there?

2. Please describe where you work.

3. Tell me about your healthcare/community leadership involvement?

4. Are you involved in surgical care/healthcare?

a. If so, how?

5. Do you serve rural populations?

a. If yes, can you describe the rural populations you serve?

6. What is the current state of the surgical care system for rural populations?

7. Can you identify barriers that rural populations face in order to access timely surgical care?

8. Drawing from your experience, what are the reasons behind why rural patients delay in:

a. Seeking surgical care?

b. Reaching surgical care?

c. Receiving surgical care?

9. From your perspective as healthcare/community leader, what can be done in order to optimize timely access to surgical care for rural patients?

10. Can you identify an area that you specifically could potentially influence in order to optimize the surgical care system for rural patients?

11. Can you identify an area/s outside of your power that would need to be modified in order to optimize surgical care access? 
12. What is the current state of the supply chain needed in the surgical care system/healthcare system?

13. Can you identify areas where supply chain can be optimized in order to improve timely access to surgical care?

14. How can communication be optimized between different key surgical stakeholders: patients, local leaders, hospital/surgical facilities (private and public), surgeons/anesthesiologist/healthcare provider and government officials in order to improve the surgical/healthcare system?

15. Do you consider if mobile surgery could be effective at providing surgical care for rural population?

a. Please comment: if yes,

i. why?

ii. How?

b. If no, who not?

16. Do you have additional comments that would help us understand barriers and delays confronted by rural patients?

17. Do you have additional comments that would help us understand how optimize access to timely surgical care for rural patients?

18. Would you like to add any other comments?

Thank you for your time. 